\title{
Dysphagia as a risk factor for mortality in Niemann-Pick disease type C: systematic literature review and evidence from studies with miglustat
}

\author{
Mark Walterfang ${ }^{1 *}$, Yin-Hsiu Chien ${ }^{2}$, Jackie Imrie ${ }^{3}$, Derren Rushton ${ }^{4}$, Danielle Schubiger ${ }^{1}$ and Marc C Patterson ${ }^{5}$
}

\begin{abstract}
Niemann-Pick disease type C (NP-C) is a rare neurovisceral disease characterised by progressive neurological deterioration and premature death, and has an estimated birth incidence of 1:120,000. Mutations in the NPC1 gene (in 95\% of cases) and the NPC2 gene (in approximately $4 \%$ of cases) give rise to impaired intracellular lipid metabolism in a number of tissues, including the brain. Typical neurological manifestations include vertical supranuclear gaze palsy, saccadic eye movement abnormalities, cerebellar ataxia, dystonia, dysmetria, dysphagia and dysarthria. Oropharyngeal dysphagia can be particularly problematic as it can often lead to food or fluid aspiration and subsequent pneumonia. Epidemiological data suggest that bronchopneumonia subsequent to food or fluid aspiration is a major cause of mortality in NP-C and other neurodegenerative disorders. These findings indicate that a therapy capable of improving or stabilising swallowing function might reduce the risk of aspiration pneumonia, and could have a positive impact on patient survival. Miglustat, currently the only approved disease-specific therapy for NP-C in children and adults, has been shown to stabilise key neurological manifestations in NP-C, including dysphagia. In this article we present findings from a systematic literature review of published data on bronchopneumonia/aspiration pneumonia as a cause of death, and on the occurrence of dysphagia in NP-C and other neurodegenerative diseases. We then examine the potential links between dysphagia, aspiration, pneumonia and mortality with a view to assessing the possible effect of miglustat on patient lifespan.
\end{abstract}

Keywords: Niemann-Pick disease type C, Dysphagia, Mortality, Swallowing, Pneumonia, Aspiration, Miglustat.

\section{Introduction}

Niemann-Pick disease type C (NP-C) is a rare neurovisceral disease characterised by progressive neurological deterioration and premature death, and has an estimated birth incidence of 1:120,000 [1,2]. It is caused by the autosomal recessive inheritance of mutations in either of the two genes, $N P C 1$ (in approximately $95 \%$ of cases) or NPC2 (in approximately $4 \%$ of cases) [3-5]. Mutations in either of these genes result in impaired metabolism of endocytosed cholesterol and intracellular accumulation of a number of lipid moieties in various tissues, particularly in the brain $[1,6]$.

Patients with NP-C usually present with one or more neurological signs during childhood [1], although an

\footnotetext{
*Correspondence: mark.walterfang@mh.org.au

'Royal Melbourne Hospital and Melbourne Neuropsychiatry Centre,

Melbourne 3050, Australia

Full list of author information is available at the end of the article
}

increasing number of patients with adult onset of neurological manifestations are being diagnosed based on late-onset neurological signs and psychiatric manifestations [7-9]. The age at onset of neurological manifestations has a major influence on the rate of disease progression and prognosis. In general, patients with neurological onset early in life deteriorate faster and have a shorter life expectancy than those with adult onset [1,10-14].

The clinical presentation of NP-C is extremely heterogeneous. Systemic symptoms such as neonatal jaundice and hepatosplenomegaly usually occur early in the course of the disease $[1,15]$. Typical neurological manifestations include vertical supranuclear gaze palsy (VSGP), saccadic eye movement (SEM) abnormalities, cerebellar ataxia, dystonia, dysmetria, dysarthria and dysphagia [1]. These neurological signs arise at different ages, but invariably progress over time $[10,16]$.

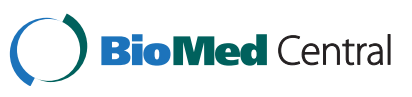


Dysphagia occurs in most NP-C patients at some point in the disease course, ranging in severity from occasional swallowing difficulties to loss of swallowing function necessitating placement of a nasogastric tube or gastrostomy feeding [10]. Dysphagia of neurological origin arises primarily from impairment in the oral and pharyngeal phases as opposed to the later oesophageal phases of swallowing, and as such is defined as oropharyngeal dysphagia [17]. Oropharyngeal dysphagia disrupts feeding but, more significantly, it increases the risk of aspiration. In NP-C, it is contributed to by bulbar motor dysfunction, dystonia, and reduced sensation. Patients with more severe neurological involvement generally have more severe dysphagia, and worsening neurological involvement correlates with a higher risk of aspirating food or fluid [18]. It is therefore recommended that patients with impaired swallowing function be closely monitored to avoid serious lung infections secondary to aspiration [15] and to ensure adequate nutrition.

Data from epidemiological studies suggest that bronchopneumonia subsequent to food or fluid aspiration is a major cause of mortality in NP-C and other neurodegenerative disorders. While precise causes of death are not consistently reported in NP-C, two studies have identified bronchopneumonia as the leading cause of death in two separate NP-C patient cohorts, accounting for approximately two-thirds of patients [19,20]. Marik et al. recognised aspiration pneumonia as the leading cause of death among a range of neurodegenerative disorders [21]. Among factors known to contribute to the development of aspiration pneumonia (e.g., poor oral hygiene, sleep disorders, emesis), dysphagia is considered to contribute by far the greatest risk [22].

Substrate reduction therapy with miglustat (Zavesca; Actelion Pharmaceuticals) was first approved for treatment of progressive neurological deterioration in children and adults with NP-C in Europe in 2009, and has since been approved in a number of other countries [23]. The primary therapeutic mode of action of miglustat in NP-C is thought to be the reduction of glucosylceramide-based glycosphingolipid synthesis in the CNS, through the reversible inhibition of glucosylceramide synthase [15,24]. In clinical studies miglustat therapy stabilised key neurological manifestations of the disease in adults and children [25-27]. While experience with the use of miglustat in clinical practice settings is increasing [11,18,28-31], published data on long-term clinical outcomes in NP-C patients receiving miglustat remain relatively scarce, owing to the rarity of the disease.

The progressive neurodegenerative nature of NP-C and its typically delayed diagnosis means that disease stabilisation, or a reduced rate of disease progression, are the best attainable goals for long-term disease-specific therapy, given that most patients have a substantial burden of disease by the time of diagnosis [15]. Published data suggest that therapies capable of stabilising/improving swallowing function can reduce the risk of aspiration pneumonia and, potentially, reduce mortality risk [32,33]. In this article we review published information on the most common reported causes of death in NP-C, and evaluate disease factors that might contribute to an increased risk of mortality. We then examine the impact of miglustat on these disease factors to gain insight into the potential effects of this drug on patient lifespan.

\section{Systematic review methodology Epidemiological research}

A series of systematic epidemiological literature reviews was conducted using the Embase online database in March 2011, to investigate several disease-related factors. Owing to the rarity of the disease and to limited long-term outcome reporting in NP-C (such as precise causes of death), literature reviews examining disease factors specific to NP$\mathrm{C}$ were conducted in parallel with searches on a range of other neurodegenerative diseases. We compared outcomes data in NP-C with those from disorders with similar motor manifestations (particularly dysphagia), and similar neurodegenerative courses [34,35]. Data from patients with acute stroke were also evaluated because of the frequency of dysphagia following stroke [36]. Searches were performed to investigate the following disease-related factors:

1. Causes of death in NP-C (key terms: NP-C, mortality, cause of death)

2. Causes of death in progressive neurodegenerative disease in general (key terms: mortality, neurodegenerative disease $\mathrm{e}^{*}$ )

3. The prevalence of dysphagia in neurodegenerative diseases including NP-C (key terms: swallowing, dysphagia, neurodegenerative disease*, NP-C)

4. The association between dysphagia and aspiration pneumonia (key terms: swallowing, dysphagia, aspiration pneumonia, neurodegenerative disease*, NP-C, stroke, traumatic brain injury)

5. The association between aspiration pneumonia and mortality (key terms: death, cause of death, mortality, aspiration pneumonia, neurodegenerative disease*, NP-C, stroke, traumatic brain injury).

*Neurodegenerative diseases included some or all of: Huntington's chorea, Parkinson's disease [PD], amyotrophic lateral sclerosis [ALS], multiple sclerosis [MS], Alzheimer's disease [AD], frontotemporal dementia [FTD], Wilson's disease, olivopontocerebellar atrophy [OPCA], progressive supranuclear palsy [PSP], neuroferritinopathy, motor neurone disease (MND), neuromuscular disease and epilepsy. 
Literature data sets were fine-tuned using a standard set of inclusion and exclusion criteria. Only original research reports containing numerical data from clinical assessments were included. Non-English articles were excluded, as were reports based on preclinical data or any duplicate reports of previously published data sets.

\section{Research on the effects of miglustat on dysphagia and outcomes in NP-C}

Because NP-C is rare, we conducted broad literature searches to capture any randomised controlled trials comparing miglustat with standard (symptomatic) medical management, as well as evidence from nonrandomised studies providing any additional data on miglustat treatment in patients with NP-C.

Initial searches of Medline, Embase, the Cochrane Central Register of Controlled Trials, the National Institutes of Health (NIH) clinical trials database (Clinicaltrials.gov) and the Australian Clinical Trials Registry (Anzctr.org.au) were conducted in January 2010. A further search was then repeated in March 2011 to identify any updated published information. In addition, manual searches were conducted using reference lists from all relevant articles identified in the automated database searches.

\section{Literature review findings}

\section{Causes of death in NP-C}

Out of 741 potentially relevant articles, seven were identified that specifically discussed cause(s) of death in patients with NP-C [8,19,20,37-40]. Additional studies were identified during the literature search, but no data on causes of death were reported. See Additional file 1: Table S1, for a full listing of literature search findings.

Overall, the identified studies included data from 82 patients with NP-C. While there was no specific reference to 'aspiration pneumonia' in the identified publications, the most frequent reported cause of death was bronchopneumonia, based mainly on a retrospective case study analysis in 43 UK patients [20] and a chart review of 20 patients in Nova Scotia [19]. While no actual numbers of deaths related to specific causes were reported in the UK-based study, the major cause of death was cited as bronchopulmonary failure with secondary infection [20]. In the Nova Scotia cohort, swallowing difficulties were reported in $100 \%$ of patients, and drooling in 95\%; pneumonia was cited as the cause of death in 12/20 (60\%) patients.

In the wider community, aspiration pneumonia occurs more frequently among individuals who are at risk of aspiration than is reported; in many cases, it goes unrecognised and is not recorded [22]. In the following discussions regarding these and other data, it is important to consider a number of factors that contribute to the under-reporting and/or under-recognition of the role of aspiration pneumonia as a cause of death.

Disease coding systems can complicate the accurate recording of precise causes of death in patients with neurodegenerative diseases. Some coding systems restrict physicians to recording progression of the underlying (primary) disease on death certificates [41,42]. Some physicians also prefer to record a cause of death as 'pneumonia' rather than 'aspiration pneumonia' [34]. In a large-scale study of dementia patients in England and Wales from 1979 to 2004 [41], only half of deaths that were attributed to 'AD' according to the ICD-10 classification would have been coded as such based on ICD-9 criteria, which allowed the specification of bronchopneumonia and dementia. Similar results were reported for PD patients [41].

There is currently a lack of specific or sensitive markers for aspiration, which limits the ability to discern aspiration pneumonia from other forms of pneumonia and results in deaths related to aspiration being recorded under the term 'pneumonia' $[21,43,44]$. Aspiration is considered the predominant mode of infection in nosocomial pneumonia, mostly among the elderly [34]. However, aspiration events are rarely witnessed in patients with aspiration pneumonia, where the clinical presentation typically matches that of community-acquired pneumonia [21]. This is particularly relevant in patients with 'silent aspiration', where aspiration occurs without obvious clinical signs of swallowing difficulty [45].

Because of the limited number of precise data on death in NP-C, it may be instructive to refer to data from other, more frequent neurodegenerative diseases that bear similarities to NP-C at the cellular and phenotypic level. For instance, there are a number of common aetiological factors between Huntington's chorea and NP-C at the level of membrane trafficking [46], and patients with these two conditions share certain symptomatologic similarities such as dystonia, motoric difficulties that impair manual and oropharyngeal coordination, and impairments to memory and executive functioning that regulate feeding behaviour and the use/ retention of safe swallowing strategies. Similarly, AD and NP-C share certain neurodegenerative pathways and neuropathological signs $[47,48]$.

\section{Causes of death in other neurodegenerative diseases}

Data on causes of death in a variety of neurological diseases including Huntington's chorea, amyotrophic lateral sclerosis (ALS), Alzheimer's disease (AD), frontotemporal dementia (FTD), multiple sclerosis (MS), olivopontocerebellar atrophy (OPCA), Parkinson's disease (PD), progressive supranuclear palsy (PSP) and Wilson's disease are listed in Additional file 2: Table S2. 
Cause-of-death data were available from 24 out of 1,180 potentially relevant articles. Across all the diseases studied, $20 \%$ of patients were classified as having died due to 'aspiration pneumonia'. Among patients with Huntington's chorea, which probably most resembles $\mathrm{NP}-\mathrm{C}$ in terms of the profile of motor deficits seen, data from the automated literature search indicated that the overall proportion of deaths due to 'aspiration pneumonia' or 'pneumonia' was $37.5 \%$ (see Additional file 1: Tables S1, Additional file 2: Table S2, Additional file 3: Table S3, Additional file 4: Table S4 and Additional file 5: Table S5). A further two studies were identified during manual searching. In one study, 'pneumonia' was the reported cause of death in 55\% of patients, among whom $89 \%$ died due to 'aspiration pneumonia' [44]. In the other study, $42 \%$ of deaths were recorded as being due to 'pneumonia' [49]. Surprisingly, 'aspiration pneumonia' or 'pneumonia' were only recorded as causes of death among $11 \%$ of ALS patients, despite that fact that most (if not all) ALS patients in the later stages of the disease show some degree of dysphagia [34].

In non-quantitative articles that were excluded from the numerical analysis, aspiration pneumonia was stated as a major cause of death in patients with neurodegenerative disorders, particularly in those with dysphagia due to neurological deterioration [21,22,35]. Precise causes of death were difficult to quantify due to inconsistent reporting, even in studies of more common dementias (where 'aspiration pneumonia'/'pneumonia' caused $45 \%$ of deaths [50]) and PD (where aspiration pneumonia caused up to $48 \%$ of deaths).

Dysphagia in NP-C and other neurodegenerative diseases Among 821 potentially relevant articles identified in the search designed to quantify the prevalence of dysphagia in NP-C and other neurodegenerative diseases, data from 52 studies were included for analysis (see Additional file 3: Table S3 for full data listing). Overall, 4,065 from a total of 14,664 patients (28\%) had dysphagia. Figure 1 summarises the prevalence of dysphagia in each condition for which quantitative data were available.

The estimated incidence of dysphagia in a large study including PD patients was low at only $8 \%$ [51], bringing the unweighted average prevalence for PD down to $25 \%$. However, this study relied on ICD-9 codes for dysphagia. The authors acknowledge that this figure is therefore likely an underestimate. When the results from this study are disregarded, the rate among PD patients becomes $43 \%$, which is closer to other reported findings [52]. Further, the overall incidence for dysphagia among all patients with neurodegenerative diseases becomes $35 \%$.

The incidence of dysphagia reported among ALS patients was surprisingly low (24\%). However, the ALS data were strongly influenced by one large study in

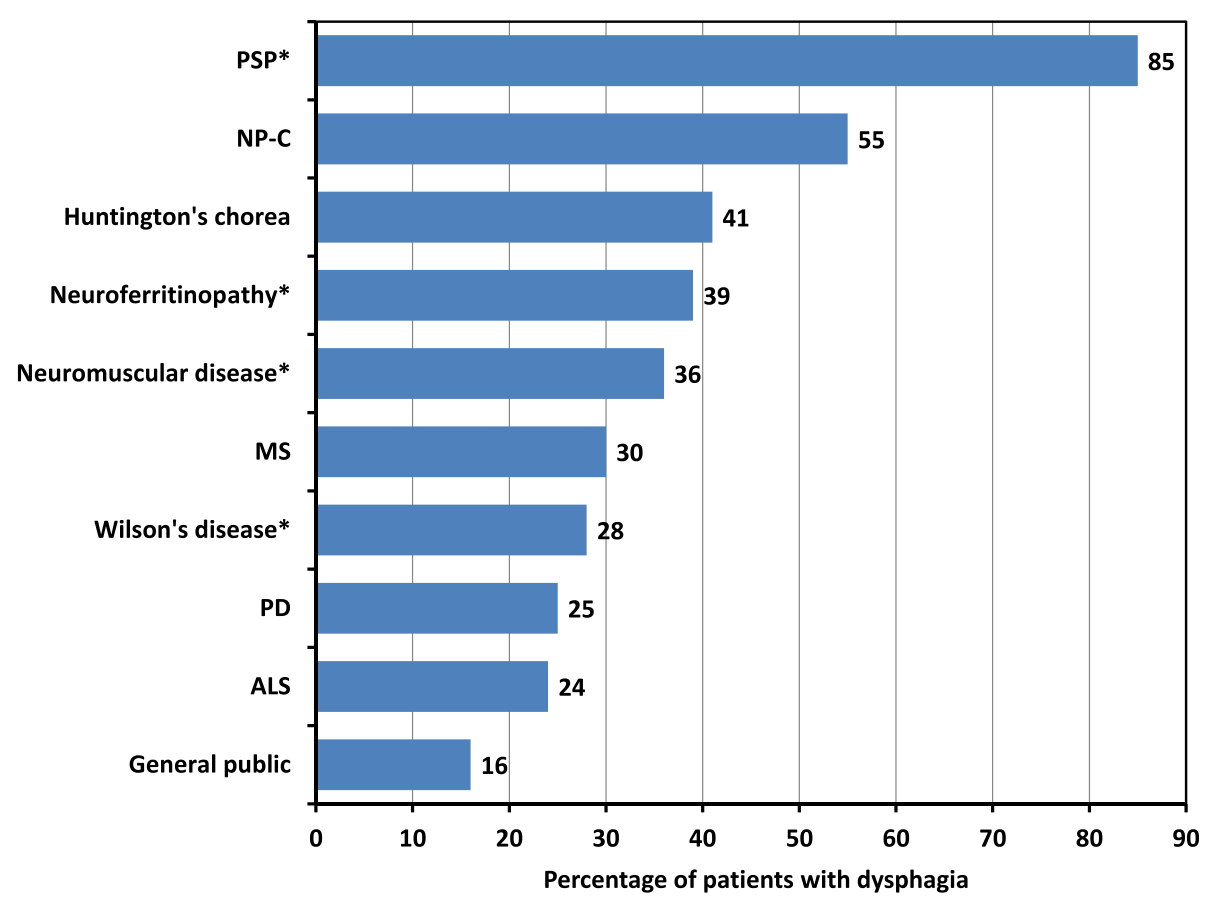

Figure 1 Prevalence of dysphagia in Niemann-Pick disease type C (NP-C) and other neurodegenerative diseases. ${ }^{*}$ Conditions where data were available from only one study. ALS, amyotrophic lateral sclerosis; MS, multiple sclerosis, PD, Parkinson's disease; PSP, progressive supranuclear palsy. 
3,428 patients that included a range of patients with different ages at onset, and therefore likely comprised a high proportion of patients with early-to mid-stage disease [53]. Dysphagia was reported in $30-50 \%$ of patients among other ALS studies, and has been reported in most if not all late-stage ALS patients [34].

Among all neurodegenerative diseases PSP appeared to be associated with the greatest prevalence of dysphagia (85\%), although these data were based on only one identified study with evaluable data. Patients with NP-C showed the second-highest prevalence (55\%), which is substantially greater than the overall average prevalence among neurodegenerative disease patients. Further, this figure is likely an underestimate, as most patients included in NP-C studies were in the early stages of disease and were being treated with miglustat.

\section{Association between dysphagia and aspiration pneumonia}

Twelve out of 364 potentially relevant articles reported data on the association between dysphagia and aspiration pneumonia in patients with neurodegenerative disease, stroke or traumatic brain injury (see Additional file 4 for full data listing). Based on relative risk analyses, these published data consistently indicated an increased risk of aspiration pneumonia where dysphagia was present (Table 1). Relative risk values ranged from 1.6 (95\% CI 0.1, $38.0)$ to 126 (95\% CI 8, 2065).

Data from this literature search were combined for meta-analysis (Figure 2). After exclusion of one very large study [56], which included data from 77,540,204 general hospital patients resulting in unacceptably high weighting of the overall sample (accounting for $99.8 \%$ of all included patients), odds ratios indicated a highly significantly increased risk of aspiration pneumonia among patients with dysphagia. The overall odds ratio for developing pneumonia was 16.85 (95\% CI 9.21, 30.83), with values ranging from 1.7 (95\% CI $0.1,42.4)$ to 174 (95\% CI 10, 2,952). Analysis including data from the large general hospital population study confirmed this finding (odds ratio, 14.1 (95\% CI 13.9, 14.3))

\section{Association between aspiration pneumonia and mortality} Five of 243 potentially relevant articles were identified that reported data on both aspiration pneumonia and mortality outcomes in patients with PD, stroke or epilepsy (see Additional file 5: Table S5 for full data listing). One extra article was identified in an additional hand search of the literature that contained data from a mixed population of patients with PD, MND, AD or Huntington's chorea [33]. No published articles were identified that reported data on both aspiration pneumonia and mortality in patients with NP-C.
Table 1 Relative risk of aspiration pneumonia in patients with neurodegenerative disease or stroke and dysphagia

\begin{tabular}{lcc}
\hline Source, author (year) & Patient type & Relative risk \\
\cline { 3 - 3 } & & $\mathbf{( 9 5 \% ~ C l )}$ \\
\hline Ahn et al. (2010) [54] & Stroke & $106(6,1729)$ \\
Alshekhlee et al. (2010) [55] & Stroke & $30(4,218)$ \\
Altman et al. (2010) [56] & Dysphagia patients & $13(12,13)$ \\
Aviv et al. (1997) [57] & Stroke & $13(1,216)$ \\
Chua and Kong (1996) [58] & Stroke & $4.6(1.0,20.5)$ \\
Daniels et al. (1998) [36] & Stroke & $1.6(0.1,38.0)$ \\
James (1998) [59] & Stroke & $4.1(1.5,11.4)$ \\
Meng et al. (2000) [60] & Stroke & $2.4(0.1,40.1)$ \\
Perry and McLaren (2000) [61] & Stroke & $21.0(2.8,155.9)$ \\
Schurr et al. (1999) [62] & Traumatic brain injury & $2.9(0.1,67.3)$ \\
Spencer et al. (2009) [63] & Stroke & $11.0(1.0,178.3)$ \\
Sung et al. (2010) [64] & Parkinson's disease & $126(8,2065)$ \\
\hline *Relative risk calculated using Mantel-Haenszel fixed effects method.
\end{tabular}

The relative risk $(95 \% \mathrm{CI})$ of mortality among patients with aspiration pneumonia in the identified studies ranged from $1.51(1.35,1.69)$ to $3.42(0.82,14.35)$ (Table 2). When data were combined in a meta-analysis to evaluate the relationship between these two outcomes, patients experiencing aspiration pneumonia were seen to have an increased risk of mortality (Figure 3 ). The overall odds ratio for mortality was 3.23 (95\% CI 2.46, 4.25).

\section{Epidemiological research: overall findings}

The quantitative analysis of causes of death in NP-C patients is currently limited by the scarcity of relevant published studies, with few reports containing mortality data. There was limited but consistent reporting of bronchopneumonia as the most common cause of death in NP-C, accounting for over $60 \%$ of patients $[19,20]$. Supplemental analysis of data in other neurodegenerative diseases that feature dysphagia showed 'aspiration pneumonia' or 'pneumonia' reported as a cause of death in over $20 \%$ of patients. However, this is considered to be vastly underestimated due to a number of factors that contribute to under-reporting of aspiration pneumonia as cause of death.

The analysis of published data in NP-C and a range of other neurodegenerative diseases showed that dysphagia is a frequent symptom, particularly in NP-C and PSP. Further, relative risk data and meta-analyses provide clear evidence that patients with dysphagia are at an increased risk of developing aspiration pneumonia, and that there is a strong link between the occurrence of aspiration pneumonia and mortality risk. With these links now established, the following sections specifically examine the effects of miglustat therapy on dysphagia and mortality risk in NP-C. 


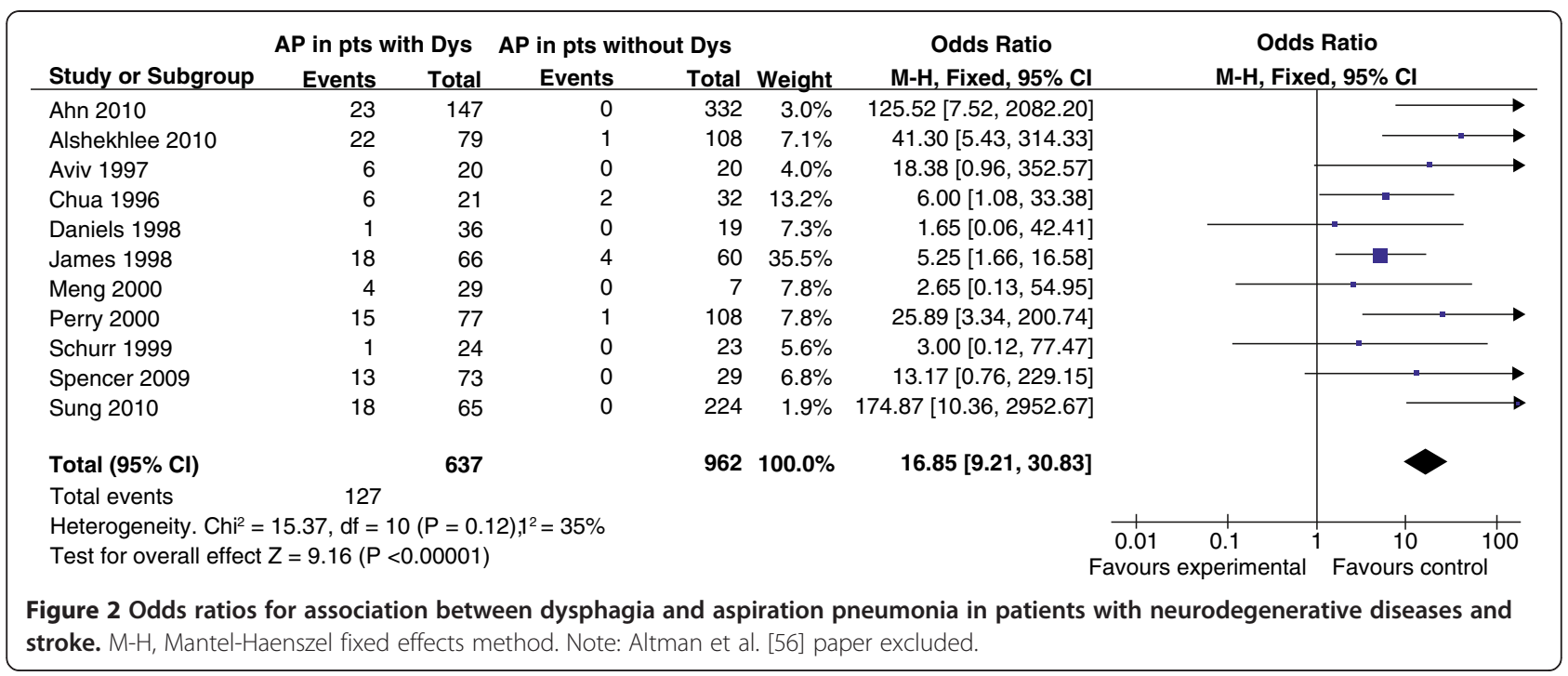

\section{Studies and methods assessing the effects of miglustat on dysphagia in NP-C}

All published clinical studies providing data on swallowing function in miglustat-treated patients are summarised in Table 3.

\section{Swallowing assessments based on clinical judgment}

Swallowing function data were available from a 12month randomised, controlled trial that assessed the efficacy, safety and tolerability of miglustat $200 \mathrm{mg}$ t.i.d. in juvenile and adult patients aged $\geq 12$ years $(n=29)$, compared with standard care [25]. Findings were also reported from a parallel non-controlled sub-study of this trial, which assessed miglustat in children aged 411 years $(n=12)$ [25].

Long-term data from patients continuing miglustat therapy during 12-month open-label extensions of the main juvenile/adult study $(\mathrm{n}=21)$ and the paediatric sub-study $(n=10)$ have since been published $[26,27]$. In

Table 2 Relative risk of mortality in patients with neurodegenerative disease or stroke and aspiration pneumonia

\begin{tabular}{lcc}
\hline Source, author (year) & Patient type & Relative risk* \\
\cline { 3 - 3 } & & $\mathbf{( 9 5 \% ~ C l )}$ \\
\hline Ali et al. (2008) [65] & Stroke & $3.42(0.82,14.35)$ \\
Amare and Amanuel (2008) [66] & Epilepsy & $1.90(0.88,4.10)$ \\
Aslanyan et al. (2004) [67] & Stroke & $2.58(1.82,3.66)$ \\
Fernandez and Lapane (2002) [68] & $\begin{array}{c}\text { Parkinson's } \\
\text { disease }\end{array}$ & $1.51(1.35,1.69)$ \\
Low et al. (2001) [33] & Dysphagia & $2.58(1.77,3.78)$ \\
Marwat et al. (2010) [69] & patients & \\
\hline
\end{tabular}

*Relative risk calculated using Mantel-Haenszel fixed effects method. each of these reports dysphagia was assessed based on standardised clinical assessments of the patients' ability to swallow different foods (e.g. water, puree, soft pasta/ noodles, a cookie), graded using a five-point categorical scale: 'no problems swallowing,' 'mild problems', 'moderate problems', 'severe problems', or 'could not swallow at all'.

Retrospective data on swallowing function were reported in an international, multicentre, observational cohort study that evaluated neurological disease progression in patients treated with miglustat in clinical practice settings $(n=66)$ [70]. Swallowing function was evaluated based on patients' scores on the dysphagia subscale of a modified, disease-specific disability scale [12]. Using this subscale the degree of dysphagia before miglustat therapy, at treatment initiation, and after therapy was rated as 'normal' (score $=0)$, 'occasional dysphagia' (score $=0.33$ ), 'daily dysphagia' ( score $=0.66$ ), or 'nasogastric tube or gastric button feeding' (score = 1) [70]. Data then underwent categorical analysis for 'improvement', 'stabilisation' or 'worsening' of swallowing function.

\section{Swallowing assessments based on instrumental methods} Findings from instrumental, quantitative assessments of swallowing have been reported from two studies $[18,29]$. Both reports were based on longitudinal case analyses incorporating videofluoroscopic studies (VFSS), which are considered the gold standard method for studying oropharyngeal swallowing function. VFSS allow the indepth evaluation of all phases of the swallowing motion, enabling clear distinctions between oral-phase and pharyngeal phase dysfunction [71].

Fecarotta et al. reported findings from detailed serial studies of swallowing function in three female patients 


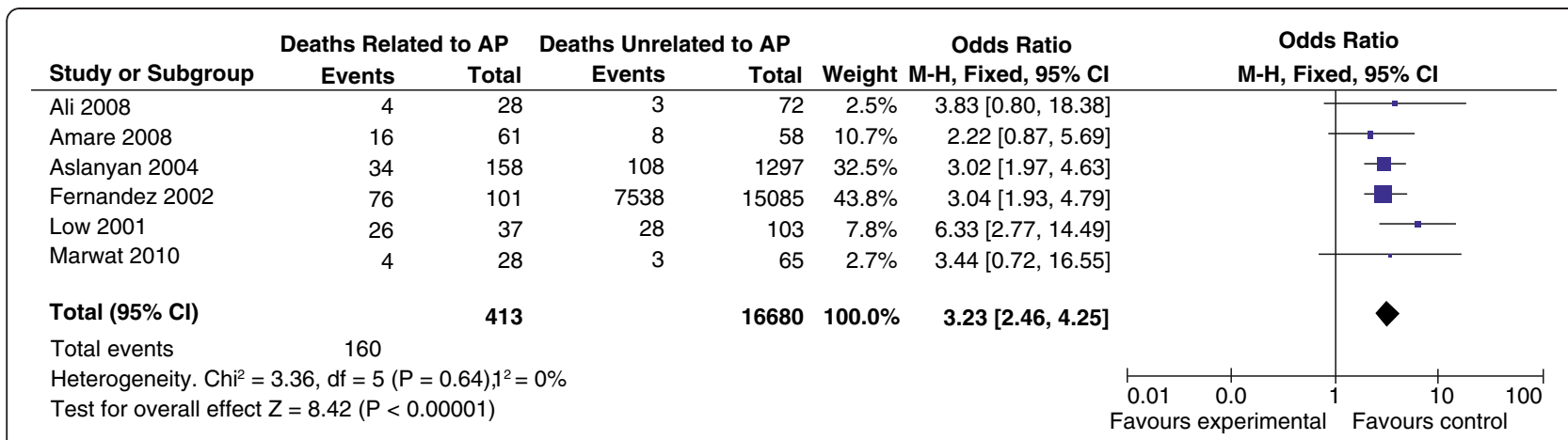

Figure 3 Odds ratios for association between aspiration pneumonia and mortality outcomes. M-H, Mantel-Haenszel fixed effects method.

with late-infantile or juvenile-onset NPC1 and one male patient with severe early-infantile onset NPC2 [18]. These patients received miglustat therapy, dosed according to BSA for between 3 and 4 years. The severity of dysphagia was evaluated at 2-6 monthly intervals based on an adapted version of the 6-point Dysphagia Severity Score (DSS) [71], which ranges from normal swallowing $($ score $=0)$ to severe dysphagia with potential for aspiration (score $=5)$. A 7-point Penetration-Aspiration Score (PAS) was also applied at each VFSS assessment to quantify penetration/aspiration in the airways according to published methods [71]; again, higher scores on this scale indicated more severe impairment. VFSS were also conducted in parallel with NP-C disability scale assessments to assess correlations between swallowing function, overall neurological deterioration (based on composite disability scores [70]) and the dysphagia subscale scores.

Chien et al. reported data from two young symptomatic male patients with juvenile-onset NP-C who completed 1 year of miglustat therapy, dosed according to body surface area. One patient had severely impaired swallowing function, and the second displayed normal swallowing but impaired language and speaking ability prior to miglustat therapy [29]. Videotapes of VFSS of liquid barium swallowing were analysed by a single radiologist based on the Han functional dysphagia scale [72]. Scores were assigned to 11 variables that covered the 'entire swallowing cycle' or 'all aspects of the oropharyngeal swallow'. Individual scores assessing each of these variables were summated to provide a total functional dysphagia score ranging from 0 (no impairment) to 100 (severe impairment).

\section{Results from studies of the effects of miglustat on dysphagia in NP-C Categorical data findings}

Based on clinical judgment, miglustat was reported to stabilise or improve swallowing function in a substantial proportion of patients with NP-C.
In the randomised controlled trial, improvements were seen in the ability to swallow water for six patients (30\%), puree for three patients (15\%), soft lumps for three patients $(15 \%)$, and a third of a cookie for seven patients (35\%) after 12 months of therapy [25]. The proportions of miglustat-treated juvenile/adult patients reporting no difficulty swallowing water, puree and onethird of a cookie after 12 months of miglustat therapy increased from baseline by $10-25 \%$ (Figure 4). In contrast, the proportions of juvenile/adult patients on standard care who showed no difficulty swallowing were either equal to or lower than baseline at 12 months.

In the non-controlled extension study [27], swallowing was improved or stable (versus baseline) in $86 \%$ of all juvenile/adult patients who completed 12 months of miglustat therapy $(\mathrm{n}=21)$, and in $79-93 \%$ of those completing 24 months on miglustat $(n=15)$, depending on the substance assessed.

Swallowing difficulties were less common in the paediatric sub-study population (recorded in only 33\% of patients at baseline) [25]. Over $80 \%$ of children swallowed all four test substances easily before treatment was started. It was therefore anticipated that improvements in swallowing were not likely. A worsening in the ability to swallow water, puree, soft lumps and one-third of a cookie was noted after 12 months of therapy in three patients (27\%), two patients $(18 \%)$, one patient (9\%) and two patients (18\%), respectively. However, among 10 paediatric patients who participated in and completed extension treatment, only one showed deterioration in the ability to swallow one-third of a cookie after 24 months of therapy. All other patients showed no change in swallowing function from baseline.

Dysphagia assessments in NP-C patients included in the retrospective observational NP-C cohort indicated similar findings among patients treated outside the context of clinical trials [70]. The retrospective cohort comprised 66 patients with a mean (SD) age at diagnosis of 9.7 (7.6) years; the mean (SD) age at treatment start was 12.8 (9.5) years. On average, patients had been under 
Table 3 Summary of randomised and non-randomised studies with information on the effects of miglustat on dysphagia

\begin{tabular}{|c|c|c|c|}
\hline Trial ID [reference] & Design & Treatment & Patients \\
\hline \multirow[t]{2}{*}{ OGT-918-007 [25] } & $\begin{array}{l}\text { 12-month } \\
\text { randomised, } \\
\text { controlled Phase II } \\
\text { study comparing } \\
\text { miglustat with } \\
\text { standard } \\
\text { (symptomatic) } \\
\text { therapy }\end{array}$ & $\begin{array}{l}\text { Main study: miglustat } \\
200 \text { mg t.i.d. }(n=20) \text { vs. } \\
\text { standard care }(n=9)\end{array}$ & $\begin{array}{l}\text { Main study: male } \\
\text { and female adults } \\
\text { and juveniles (aged } \\
\geq 12 \text { years) }\end{array}$ \\
\hline & & $\begin{array}{l}\text { Sub-study: miglustat } \\
200 \text { mg ti.id adjusted } \\
\text { for BSA }(n=12)\end{array}$ & $\begin{array}{l}\text { Sub study: male and } \\
\text { female children aged } \\
4-11 \text { years }\end{array}$ \\
\hline $\begin{array}{l}\text { OGT-918-007 } \\
\text { ext (a) [27] }\end{array}$ & $\begin{array}{l}\text { Prospective, } \\
\text { non-controlled, } \\
\text { 12-month extension to } \\
\text { OGT-918-007 }\end{array}$ & Miglustat 200 mg ti.i.d. & $\begin{array}{l}\text { Male and female adults } \\
\text { and juveniles (aged } \\
\geq 12 \text { years) who received } \\
\text { miglustat ( } n=17 \text { ) or } \\
\text { standard care } \\
(n=8) \text { for } 12 \text { months }\end{array}$ \\
\hline
\end{tabular}

Swallowing function
Ability to swallow
different foods
( $5 \mathrm{~mL}$ of water,
1 teaspoon of puree,
1 teaspoon of soft lumps,
or a third of a cookie)

\section{Key findings}

Improved ability to

swallow water in

6 patients (30\%),

puree in 3 patients

1 teaspoon of soft lumps, (15\%), soft lumps in

and a third of a

cookie in 7 patients

(35\%) after

12 months of

miglustat therapy

Assessed at 6 and

12 months or

withdrawal/follow-up

Over $80 \%$ of

children had

normal swallowing

at baseline

Swallowing assessment

(as above) at 12 and

Swallowing improved/stable

(vs. baseline) in

$86 \%$ of patients

completing

12 months, and

79-93\% of those

completing

24 months on

miglustat

$\begin{array}{ll}\text { OGT-918-007 } & \text { Prospective, } \\ \text { ext (b) [26] } & \text { non-controlled } \\ & \text { 12-month } \\ & \text { extension to } \\ & \text { OGT-918-007 } \\ & \text { sub-study }\end{array}$

Miglustat $200 \mathrm{mg}$

t.i.d adjusted for BSA

Male and female children aged 4-11 years who

underwent 12 months of

Swallowing assessment

(as above) at 12 and

Nine patients

(90\%) had normal

miglustat therapy $(n=10)$

24 months and last visit

swallowing

function at both

baseline and

Month 24

NP-C retrospective Stage 1 survey [70]

Retrospective,

Adults $\geq 18$ years

$(n=14)$ : miglustat

$200 \mathrm{mg}$ t.i.d.

Patients previously or currently treated with miglustat in clinical

observationa

cohort study

Spanish/Portuguese

paediatric

Multicentre

cohort study [11]

observationa

chart review

Juveniles 12-17 years

$(n=13)$ : miglustat

$200 \mathrm{mg}$ t.i.d.

Paediatrics $\leq 12$ years

( $\mathrm{n}=34)$ : miglustat

adjusted for BSA

Miglustat $200 \mathrm{mg}$ t.i.d. adjusted for BSA in symptomatic patients $(n=16)$

Male and female paediatric patients treated in Spain and Portugal

Symptomatic therapy in 1 asymptomatic patient

$\begin{array}{lll}\text { Italian case } & \text { Longitudinal case } & \text { Miglustat } \\ \text { series [18] } & \text { series of Italian } & 250-300 \mathrm{mg} / \mathrm{mq} / \text { day } \\ & \text { patients } & \text { in three divided doses } \\ & & \text { for up to } 4 \text { years }\end{array}$

Male and female patients VFSS treated for $\geq 3$ years, with swallowing function assessed by VFSS $(n=4)$
Dysphagia subscale of a modified NP-C disability scale [11]

Dysphagia subscale of Continuous NP-C disability scale [12]

deterioration prior to initiation of miglustat therapy

Similar proportions of patients in each swallowing disability category at treatment start and last post-treatment assessment (stabilisation)

Stable neurological manifestations (including swallowing) patients

Smaller therapeutic benefits in younger-onset patients with greater disease severity at baseline

Improved swallowing in patients with dysphagia/aspiration at baseline $(n=3)$

No deterioration in the patient with normal swallowing at baseline in juvenile-onset 
Table 3 Summary of randomised and non-randomised studies with information on the effects of miglustat on dysphagia (Continued)

\begin{tabular}{|c|c|c|c|c|c|}
\hline \multirow[t]{2}{*}{$\begin{array}{l}\text { Taiwanese } \\
\text { data [29] }\end{array}$} & \multirow[t]{2}{*}{$\begin{array}{l}\text { Longitudinal } \\
\text { case reports }\end{array}$} & \multirow[t]{2}{*}{$\begin{array}{l}\text { Miglustat } 200 \mathrm{mg} \text { t.i.d. } \\
\text { adjusted for BSA } \\
\text { for } 1 \text { year }\end{array}$} & \multirow{2}{*}{\multicolumn{2}{|c|}{$\begin{array}{l}\text { Young male patients, } \\
1 \text { with severe } \\
\text { swallowing } \\
\text { impairment and } \\
1 \text { with impaired } \\
\text { language/speech, } \\
\text { who underwent } \\
\text { serial VFSS }\end{array}$}} & $\begin{array}{l}\text { Patient 1: substantially } \\
\text { improved swallowing } \\
\text { function after } \\
6 \text { months }\end{array}$ \\
\hline & & & & & $\begin{array}{l}\text { Patient 2: normal } \\
\text { swallowing before } \\
\text { and throughout } \\
\text { therapy }\end{array}$ \\
\hline
\end{tabular}

$\mathrm{BSA}=$ body surface area; VFSS = videofluoroscopic studies.

observation for a mean (SD) period of 3.1 (3.4) years between diagnosis and initiation of miglustat therapy.

In line with other data on the natural history of NP-C $[10,16]$, composite NP-C disability scale scores indicated marked neurological deterioration before the initiation of miglustat therapy [70]. On the dysphagia subscale, while $95 \%$ of patients had normal swallowing function or occasional dysphagia at diagnosis, this had dropped to $66 \%$ by the end of the pre-treatment observation period. In contrast, the proportion of patients with normal swallowing or occasional dysphagia after a median (range) of $1.5(0.1-4.5)$ years' miglustat treatment was almost identical to that at the start of therapy (67\%). Overall, 51/63 (81.0\%) patients showed a stable/

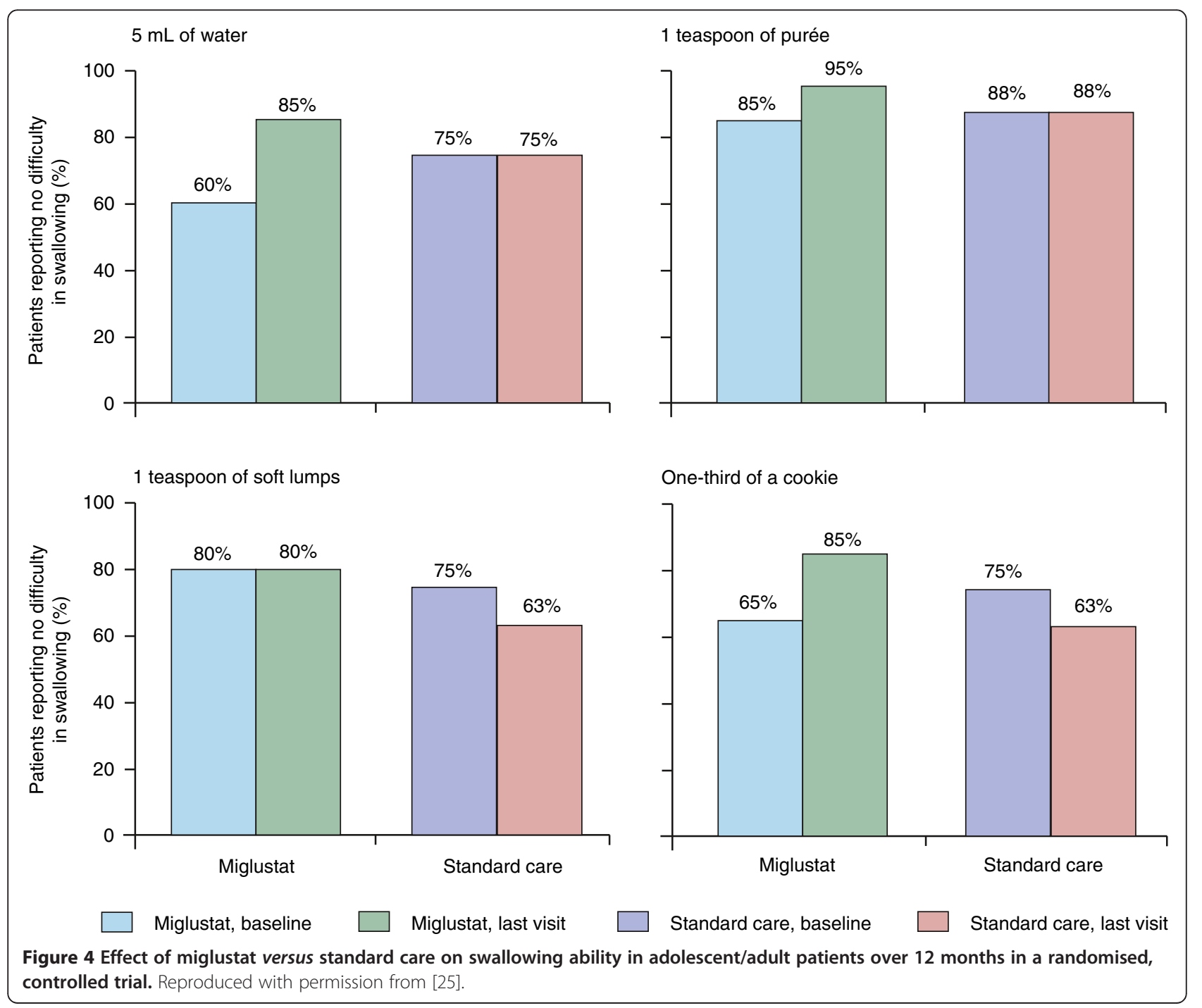


improved score on the dysphagia subscale during treatment.

\section{Instrumental assessments of swallowing}

Findings from direct instrumental assessments of the effects of miglustat on swallowing function, based on VFSS $[18,29]$, support categorical data based on clinical observation of dysphagia [25-27,70].

In the Italian case series, where serial VFSS were conducted to quantify changes in swallowing function during 36-48 months of miglustat therapy, all three patients with dysphagia at treatment start showed early improvements in swallowing ability (DSS scores), and one patient who did not exhibit dysphagia before therapy showed stable swallowing function throughout treatment [18]. Improvements in swallowing ability, particularly in terms of pharyngeal phase function, occurred in parallel with improvements or stabilisation of overall neurological manifestations assessed by composite NP-C disability scores. These apparent long-term beneficial effects of miglustat on swallowing function were associated with sustained reductions in penetration/aspiration (based on PAS scores) in all patients who showed severe swallowing impairment and aspiration prior to treatment.

Impairments of pharyngeal swallowing function tended to occur later in the course of NP-C than oralphase impairment, and more severe pharyngeal-phase involvement associated with penetration/aspiration of contrast agent in the airways was present in patients with the most severe overall neurological impairment [18]. Further, in all patients in this case series, improvements in pharyngeal swallowing function during miglustat therapy were greater, and occurred earlier, than those in the oral phase. Modest impairment in the preparatory/oral phase persisted during follow up in two patients with severe swallowing impairment (and higher NP-C disability scale scores) at treatment start.

It can be speculated that the apparent difference in the effects of miglustat on pharyngeal versus oral-phase swallowing function might reflect selective therapeutic effects of miglustat on the neurological pathways that control them [18]. While the preparatory/oral phase is activated by peripheral receptors as well as through stimulation of sensory cortical neurones, the pharyngeal and oesophageal phases are mediated by involuntary reflexes dependent on brainstem neurones. Since greater therapeutic effects were noted for pharyngeal phase swallowing, it might be that miglustat affects autonomic, brainstem-based neuronal circuits before higher, cortical centres in NP-C. The significant effects of miglustat on saccadic eye movements (which are also modulated by pathways in the brainstem) during the randomised clinical trial would certainly seem to support this [25].
Data reported from two male Taiwanese patients support findings from the Italian cohort [29]. In the patient with pronounced swallowing impairment, who had displayed neurological manifestations since 5 years of age, VFSS identified severe oropharyngeal dysphagia and prominent aspiration before miglustat treatment was initiated at the age of 14 years. Distinct improvements in swallowing function were seen after 6 months of therapy, reflected by a $25 \%$ reduction in Han functional dysphagia scale score that was sustained through to Month 12. Similar to findings reported in the Italian case series [18], this patient's improved swallowing function occurred simultaneously with improvements in ambulation [29]. The second patient, who had displayed splenomegaly since birth and behavioural problems (Asperger-like syndrome) since the age of 8 years, did not display significant swallowing impairment either before treatment or during therapy, but did show improvements in communication, social interaction and cognitive function by Month 12 [29].

\section{Data limitations}

In assessing the available published data on the effects of miglustat on dysphagia in NP-C, a number of limitations should be taken into account. NP-C is markedly heterogeneous and different patient cohorts have limited comparability, particularly in terms of age at neurological disease onset $[1,10]$. Most published evidence related to changes in swallowing function during miglustat therapy stems from subjective assessments (i.e. clinical observation and disability scales) rather than direct, quantitative swallowing studies such as those employed in the Italian cohort and Taiwanese case reports [18,29]. Dysphagia in NP-C often has mixed motor and sensory components, and silent aspiration of small or trace amounts of food or fluid is not well diagnosed without direct VFSS. Finally, the inclusion in this analysis of the retrospective miglustat observational cohort study [70] introduces potential bias, so the contribution of these data, albeit based on an established disease-specific disability scale, should be considered with caution.

\section{Longitudinal analysis of survival in miglustat- treated patients}

Analysis methods

To identify the effect of miglustat on patient survival, longitudinal statistical analyses were conducted based on all available published data from miglustat-treated patients and from an untreated cohort. Patient age at onset of neurological manifestations has previously been shown to have a strong influence on the severity, progression and prognosis of NP-C $[1,10,15,70]$. An analysis of patient survival was therefore conducted based on 
subgroups of patients, categorised by age at neurological onset, from the overall groups of untreated and treated patients identified during our analyses of published data. Patient survival was then compared between the overall treated and untreated patient groups.

Survival analyses were based on both univariate and multivariate methods. A univariate Kaplan-Meier analysis using the log-rank test evaluated survival over time, and multivariate Cox proportional hazards modelling was performed to provide estimates of overall mortality risk per treatment group and according to patient age.

Analyses in miglustat-treated patients were based on time from the start of therapy as 'age at neurological disease onset' data were not available for many patients. However, analyses in untreated patients were based on time from onset of neurological manifestations, as most patients had available data [1].

\section{Results}

The untreated group comprised patients from the French NP-C cohort [1]. This population provided longitudinal data from a total of 97 patients diagnosed in French hospitals (Table 4). Nineteen patients were excluded from this control cohort as they died during the first days or months of life, and would therefore not have been eligible to receive miglustat therapy (see Data limitations).

The treated group $(\mathrm{N}=90)$ comprised patients from the randomised controlled trial $(n=25)$ [25], the Italian cohort $(n=4)[18]$, and the retrospective observational cohort $(n=61)$ (Table 4). A number of patients were excluded from this data set due to non-availability of data, or to avoid overlap between different publications based on the same patients. Seven patients from the randomised trial data set were excluded. Six of these cases did not have a time of neurological onset recorded at baseline, disallowing their inclusion in the analysis. The seventh patient only received miglustat for 71 days, which made it very unlikely that a visible therapeutic

Table 4 Mortality in untreated and miglustat-treated NP-C patients included in survival analysis by age at neurological disease onset

\begin{tabular}{lcccc}
\hline & \multicolumn{4}{c}{ Death, $\mathbf{n}(\%)$} \\
\cline { 2 - 5 } & $\mathbf{n}$ & $\frac{\text { Untreated }}{\mathbf{( N = 9 7 )}}$ & $\mathbf{n}$ & $\frac{\text { Treated }}{\mathbf{( N = 9 0 )}}$ \\
\hline Overall & & $74(76)$ & $3(3)$ \\
Age category* & & & & \\
$<2$ years & 27 & $27(100)$ & 4 & $0(0)$ \\
2-11 years & 48 & $40(83)$ & 37 & $2(5)$ \\
$>11$ years & 22 & $7(32)$ & 49 & $1(2)$ \\
\hline
\end{tabular}

*Age at neurological symptom onset in untreated patients, and age at treatment start in treated patients. response could be expected. Taiwanese patients $(n=2)$ [29] and patients from a Spanish clinical experience cohort $(n=16)[11]$ were excluded as they formed part of the retrospective cohort.

Findings from Kaplan-Meier log-rank analysis in different age-at-onset subgroups of untreated patients were in line with previous data on the natural history of NP-C [10]. Untreated patients with neurological disease onset at $<2$ years of age showed the lowest survival rate over a 10-year period of follow up, while patients with onset aged $11+$ years had the best survival rate (Figure 5).

Analyses of survival by age at neurological onset among miglustat-treated patients were limited by low patient numbers and relative lack of long-term follow up among the available published data. No KaplanMeier curve was possible for treated patients with disease onset at $<2$ years of age as there were no deaths in this subgroup. Likewise, no meaningful analysis was possible for treated patients with neurological onset at $>11$ years of age, as only one patient in this subgroup died (early during miglustat therapy). Kaplan-Meier analysis was only possible for the 2-11 year age at onset subgroup, and showed a numerically better survival rate (2 deaths among 37 patients) during approximately 2.5 years of follow up versus the equivalent age subgroup of untreated patients (40 deaths among 48 patients).

In the overall treated versus untreated group analysis, a total of 74 patients died in the untreated group compared with just three patients in the treated group, leading to a large numerical difference in the overall mortality rates between the two groups; $76 \%$ versus $3 \%$, respectively. However, Cox proportional hazard modelling did not establish statistical significance for this difference after adjusting for age $(\mathrm{p}=0.34$; hazard ratio [95\% CI] for treated vs. untreated, $0.56 ; 0.17,1.86)$, likely due to the very low number of deaths and relatively short follow-up time in the treated group. Kaplan-Meier analysis with univariate log-rank testing identified a significant difference in mortality between the treated and untreated groups $(\mathrm{p}=0.044)$ (Figure 6).

Patient age at treatment start (in treated patients) and age at neurological symptom onset (in untreated patients) were found to have a very significant influence on survival. Cox proportional hazard modelling showed that, among all patients (treated and untreated), patients aged $<2$ years had a significantly higher mortality rate (87\%, p $<0.0001$; hazard ratio [95\% CI], 5.56 [3.08, 10.13]) compared with $49 \%$ in patients aged $2-10$ years (the reference group). Conversely, patients aged $>11$ years had a significantly lower rate $(11 \%, \mathrm{p}=0.0003$; hazard ratio $[95 \% \mathrm{CI}], 11 \%[0.10,0.51])$ compared with the reference group. 


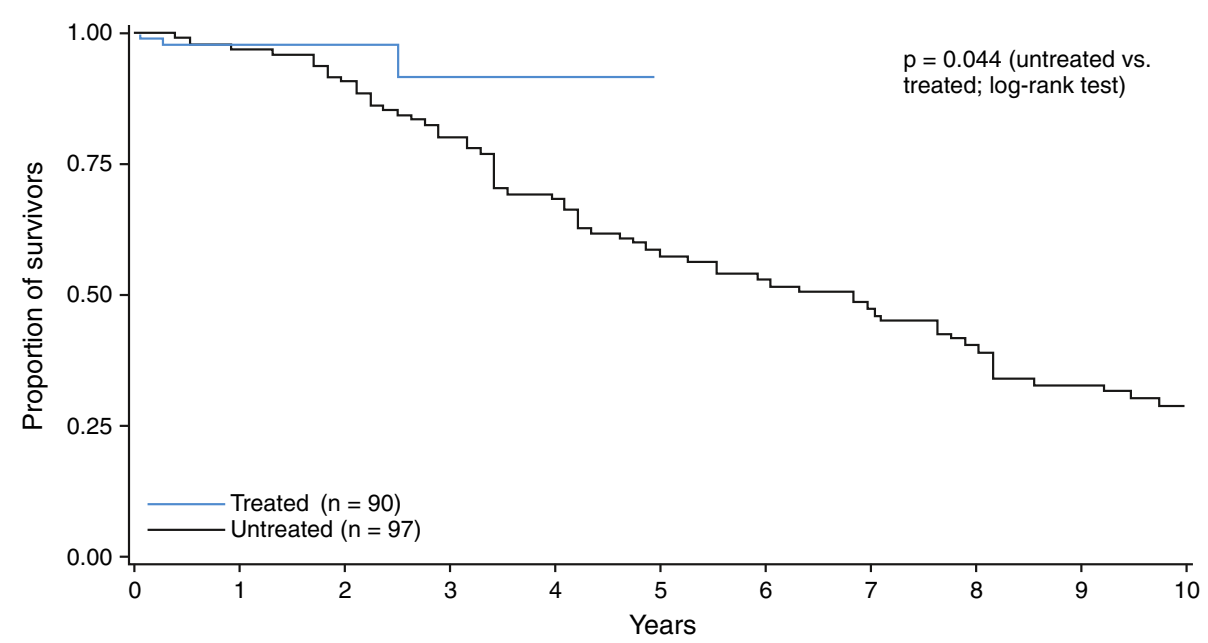

Figure 5 Influence of age at neurological onset on patient survival in untreated NP-C patients. Kaplan-Meier log-rank analysis of mortality by age at neurological disease onset in untreated patients.

\section{Data limitations}

A number of data limitations should be acknowledged in considering the results of these survival analyses, which are chiefly related to the composition and nature of the treated cohort compared with the untreated cohort. The untreated patient data used in these statistical comparisons are derived solely from the French NP-C cohort, while data from miglustat-treated patients are derived from a multinational group of patients who were included in a number of different studies.

There were large differences in the length of follow up in treated patients compared with untreated patients. Follow-up data were available from ap- proximately 1 month to 5 years among patients included in the randomised controlled trial, retrospective cohort study and Italian cohort [25,70,73], compared with approximately 23 years in the untreated cohort [1]. More specifically, while the unavailability of data for age at onset of neurological manifestations for many of the treated patients necessitated a comparison of survival from treatment start (in treated patients) with survival from neurological disease onset (in untreated patients), such a comparison presents difficulties.

Published data indicate that substantial periods of time (and likely, significant disease progression) may

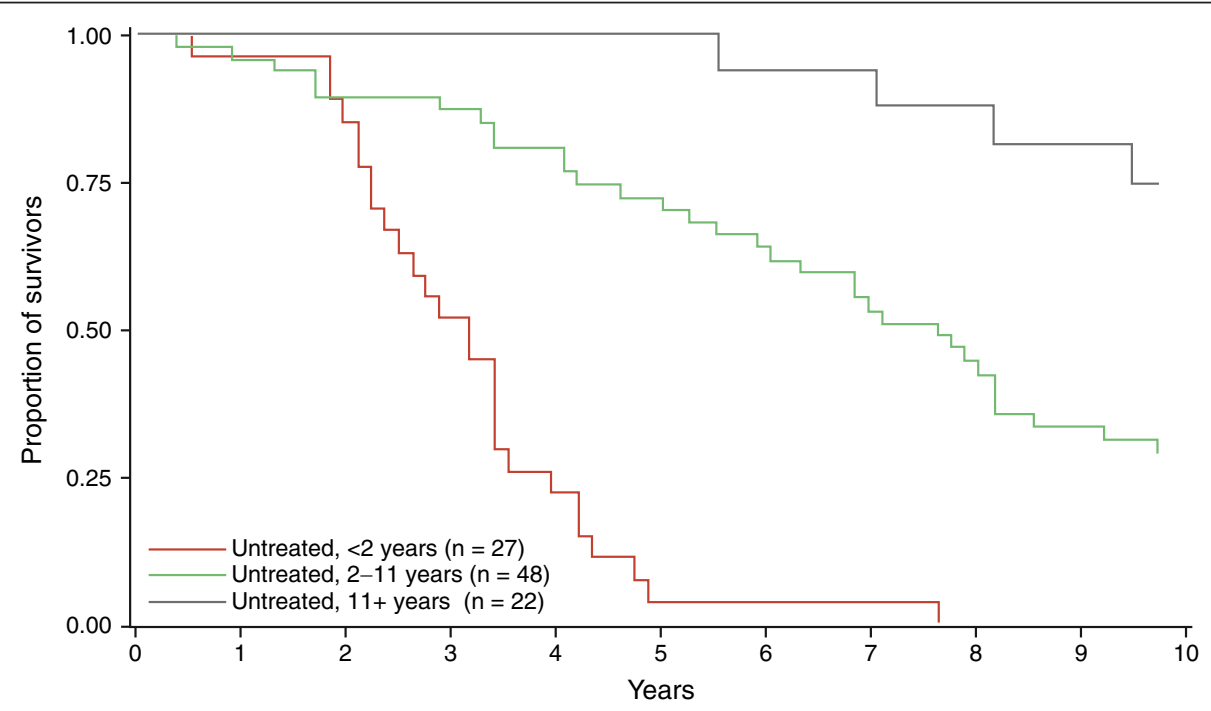

Figure 6 Influence of miglustat therapy on NP-C patient survival. Kaplan-Meier log-rank analysis of mortality since treatment start for treated patients and since age at neurological disease onset in untreated patients. 
pass between neurological onset and initiation of miglustat treatment, due either to diagnostic delay or the date at which miglustat became available (or both) $[11,70]$. Thus, some patients in the treated group might have progressed significantly before treatment initiation, while in some treated patients miglustat therapy might have been initiated after a relatively short period of time after neurological disease onset. However, given the low numbers of patients available for this assessment, it is not possible to properly assess the influence of this difference.

The untreated patient data constitute an unmatched (and generally younger) control cohort compared with the treated patients in terms of age. The mean (SD) age at treatment start in the randomised controlled trial of miglustat was 25.4 (9.8) years in adolescent/adult patients (range 12-42 years; $\mathrm{n}=20)$ and $7.2(2.5)$ years in paediatric patients (range 4-11 years; $\mathrm{n}=12$ ) [25]. The mean (SD) age at treatment start in the retrospective NP-C cohort study was 12.8 (9.5) years (range 0.6-43 years; $n=$ 66). The mean age at treatment start in the Italian case series was 8.0 (4.9) years (range 0.9-12 years; $n$ $=4)$. In contrast, the patient age at neurological symptom onset ranged between approximately 6 months and 55 years; $50 \%$ of patients were aged $<5$ years at onset, and a further $25 \%$ were aged $<10$ years. While both the Kaplan-Meier and Cox proportional hazard modelling analyses of patient survival were controlled for patient age, it cannot be discounted that age-related disease natural history might still have had an influence on the apparent difference in patient survival between the treated and non-treated groups.

It is possible that differences in regional population characteristics (e.g. lifestyle, diet, symptomatic therapies) between the treated and untreated cohorts could have contributed to, or in some other way influenced, the apparent treatment difference. However, it should be remembered that NP-C is pan-ethnic and occurs sporadically across populations, regardless of race. Differences in race per se were not expected to affect the study results.

Finally, while each of the published studies assessing miglustat therapy that were identified in this analysis made efforts to minimise bias, a number of sources of potential bias were inherent following their inclusion in the overall treated group. In particular, while there was minimal selection bias in the randomised, controlled trial of miglustat in NP-C, neither severely affected patients nor symptom-free patients were included in the study [25]. The exclusion of severely affected patients may remove those who were unlikely to improve, resulting in a positive bias (i.e. inclusion of patients more likely to improve). Conversely, non-inclusion of asymptomatic patients might exclude those whose symptom onset may be significantly delayed, thus extending the apparent survival (negative bias).

\section{Safety and tolerability of miglustat in NP-C}

While miglustat has been shown to be generally well tolerated in patients with NP-C, the perceived safety and tolerability profile of any drug can affect treatment compliance and can thus impact on clinical efficacy. Similar to previous observations in patients with Gaucher disease type 1 [23,74-78], the principal adverse events observed during clinical studies with miglustat in patients NP-C were gastrointestinal in nature [11,23,25-27,79].

During clinical trials and subsequent clinical experience, diarrhoea, flatulence, bloating and abdominal pain/ discomfort were the most commonly reported adverse events associated with miglustat, particularly during the initial weeks/months of therapy [79]. While frequently observed, these gastrointestinal disturbances are generally mild or moderate in severity and usually resolve spontaneously with time on continued therapy [79]. Where required, diarrhoea can effectively be controlled using anti-propulsive medications, used according to the respective manufacturers' prescribing information. Dietary modifications such as restriction of disaccharides or general, controlled reductions in overall carbohydrate intake can improve the gastrointestinal tolerability of miglustat, particularly if initiated before the start of therapy. Such dietary modifications should be undertaken over a course of weeks or months, with patients gradually being re-introduced to a normal diet dependent on tolerability $[79,80]$.

\section{Conclusions}

Published data indicate that aspiration pneumonia is the most common cause of death in neurodegenerative diseases, including NP-C, and that dysphagia can reliably be considered as a risk factor for mortality as it is a frequent cause of aspiration pneumonia.

Miglustat has been shown to stabilise neurological manifestations of NP-C. Beneficial effects of miglustat on swallowing function have been reported in a number of previously published studies based on clinical judgment and quantitative, instrumental VFSS.

Our findings based on systematic literature analyses and statistical survival evaluations suggest that NP-C patients receiving miglustat therapy may have a greater lifespan compared with untreated patients, and that this effect is likely related to a beneficial effect of miglustat on dysphagia. Because of the extremely variable nature of this disease and the limited published data, further, longerterm data are required to confirm this apparent effect. 


\section{Additional files}

Additional file 1: Table S1. Results for literature review examining cause of death in patients with NP-C.

Additional file 2: Table S2. Literature search results for the cause of death in neurodegenerative diseases [81-102]

Additional file 3: Table S3. Results for literature search to determine the prevalence of dysphagia in neurodegenerative diseases including NPC [103-142].

Additional file 4: Table S4. Literature search results for the association between dysphagia and aspiration pneumonia.

Additional file 5: Table S5. Literature search results regarding the association between aspiration pneumonia and mortality.

\section{Abbreviations}

AD: Alzheimer's disease; ALS: Amyotrophic lateral sclerosis; BSA: Body surface area; Cl: Confidence interval; DSS: Dysphagia severity score;

FTD: Frontotemporal dementia; HD: Huntington's disease; ICD 9/

10: International Classification of Diseases versions 9 and 10; MND: Motor neurone disease; MS: Multiple sclerosis; NP-C: Niemann-Pick disease type C; NPC1/NPC2: Specific gene mutations in patients with NP-C; OPCA: Olivopontocerebellar atrophy; PAS: Penetration-Aspiration Score; PD: Parkinson's disease; PSP: Progressive supranuclear palsy; SD: Standard deviation; SEM: Saccadic eye movement; VFSS: Videofluoroscopic studies.

\section{Competing interests}

None of the authors received honoraria for their roles in the production of this article. MW has received travel expenses, research grant funds and consulting honoraria from Actelion Pharmaceuticals Ltd. Y-HC has received consultancy honoraria from Actelion Pharmaceuticals Ltd. Jl has received travel expenses and consultancy honoraria from Actelion Pharmaceuticals Ltd. DR is an employee of Actelion Pharmaceuticals pty Ltd, Australia. DS has received an educational grant from Actelion Pharmaceuticals pty Ltd. MCP has received a research grant, travel expenses, and consulting honoraria (directed to Mayo Clinic) from Actelion Pharmaceuticals Ltd; travel expenses and consulting honoraria (directed to the Mayo Clinic) from Shire Human Genetic Therapies, an honorarium for acting as the Chair of a Data Monitoring Committee from Stem Cells Inc., and royalties as an editor of UpTo-Date. He receives research funding from the National Institutes of Health, and has received travel expenses from the Institute of Medicine for service on the Committee to Review Adverse Effects of Vaccines.

\section{Authors' contributions}

All authors have reviewed and interpreted the data, reviewed each draft of the manuscript and approved the final version for submission. All authors read and approved the final manuscript.

\section{Acknowledgments}

Matthew Reilly from InTouch Medical Ltd provided medical writing support in the preparation of this manuscript, paid for by Actelion Pharmaceuticals Ltd, Switzerland. The systematic literature services were co-ordinated by Dr Jane Adams (Pretium Pty Ltd) and the statistical analyses were conducted by Dr Richard Parsons (Pretium Pty Ltd), paid for by Actelion Pharmaceuticals Australia Pty Ltd.

\section{Author details}

${ }^{1}$ Royal Melbourne Hospital and Melbourne Neuropsychiatry Centre, Melbourne 3050, Australia. ${ }^{2}$ Departments of Paediatrics and Medical Genetics, National Taiwan University Hospital, Taipei, Taiwan. ${ }^{3}$ University of Manchester, Manchester, UK. ${ }^{4}$ Actelion Pharmaceuticals Pty Ltd, New South Wales, Australia. ${ }^{5}$ Mayo Clinic, Rochester MN, USA.

Received: 12 May 2012, Accepted: 24 September 2012 Published: 6 October 2012

\section{References}

1. Vanier MT: Niemann-Pick disease type C. Orphanet J Rare Dis 2010, 5:16.

2. Meikle PJ, Hopwood JJ, Clague AE, Carey WF: Prevalence of lysosomal storage disorders. JAMA 1999, 281:249-254.
3. Naureckiene $\mathrm{S}$, Sleat DE, Lackland H, Fensom A, Vanier MT, Wattiaux R, Jadot M, Lobel P: Identification of HE1 as the second gene of Niemann-Pick C disease. Science 2000, 290:2298-2301.

4. Steinberg SJ, Ward $\mathrm{CP}$, Fensom AH: Complementation studies in Niemann-Pick disease type $C$ indicate the existence of a second group. J Med Genet 1994, 31:317-320.

5. Carstea ED, Morris JA, Coleman KG, Loftus SK, Zhang D, Cummings C, Gu J, Rosenfeld MA, Pavan WJ, Krizman DB, et al: Niemann-Pick C1 disease gene: homology to mediators of cholesterol homeostasis. Science 1997, 277:228-231.

6. Lloyd-Evans E, Platt FM: Lipids on trial: the search for the offending metabolite in Niemann-Pick type C disease. Traffic 2010, 11:419-428.

7. Walterfang M, Fietz M, Fahey M, Sullivan D, Leane P, Lubman DI, Velakoulis $D$ : The neuropsychiatry of Niemann-Pick type $C$ disease in adulthood. J Neuropsychiatry Clin Neurosci 2006, 18:158-170.

8. Sevin M, Lesca G, Baumann N, Millat G, Lyon-Caen O, Vanier MT, Sedel F: The adult form of Niemann-Pick disease type C. Brain 2007, 130:120-133.

9. Imrie J, Vijayaraghaven S, Whitehouse C, Harris S, Heptinstall L, Church H, Cooper A, Besley GT, Wraith JE: Niemann-Pick disease type $C$ in adults. J Inherit Metab Dis 2002, 25:491-500.

10. Wraith JE, Guffon N, Rohrbach M, Hwu WL, Korenke GC, Bembi B, Luzy C, Giorgino R, Sedel F: Natural history of Niemann-Pick disease type $C$ in a multicentre observational retrospective cohort study. Mol Genet Metab 2009, 98:250-254.

11. Pineda M, Perez-Poyato MS, O'Callaghan M, Vilaseca MA, Pocovi M, Domingo R, Portal LR, Perez AV, Temudo T, Gaspar A, et al: Clinical experience with miglustat therapy in pediatric patients with Niemann-Pick disease type C: a case series. Mol Genet Metab 2010, 99:358-366.

12. Iturriaga C, Pineda M, Fernandez-Valero EM, Vanier MT, Coll MJ: Niemann-Pick $C$ disease in Spain: clinical spectrum and development of a disability scale. J Neurol Sci 2006, 249:1-6.

13. Imrie J, Dasgupta S, Besley GT, Harris C, Heptinstall L, Knight S, Vanier MT, Fensom AH, Ward C, Jacklin E, et al: The natural history of Niemann-Pick disease type $C$ in the UK. J Inherit Metab Dis 2007, 30:51-59.

14. Garver WS, Francis GA, Jelinek D, Shepherd G, Flynn J, Castro G, Walsh Vockley C, Coppock DL, Pettit KM, Heidenreich RA, Meaney FJ: The National Niemann-Pick C1 disease database: report of clinical features and health problems. Am J Med Genet A 2007, 143:1204-1211.

15. Wraith JE, Baumgartner MR, Bembi B, Covanis A, Levade T, Mengel E, Pineda M, Sedel F, Topcu M, Vanier MT, et al: Recommendations on the diagnosis and management of Niemann-Pick disease type C. Mol Genet Metab 2009, 98:152-165.

16. Yanjanin NM, Velez Jl, Gropman A, King K, Bianconi SE, Conley SK, Brewer CC, Solomon B, Pavan WJ, Arcos-Burgos M, et al: Linear clinical progression, independent of age of onset, in Niemann-Pick disease, type C. Am J Med Genet B Neuropsychiatr Genet 2010, 153B:132-140.

17. Rugiu MG: Role of videofluoroscopy in evaluation of neurologic dysphagia. Acta otorhinolaryngologica Italica: organo ufficiale della Societa italiana di otorinolaringologia e chirurgia cervico-facciale 2007, 27:306-316.

18. Fecarotta S, Amitrano M, Romano A, Della Casa R, Bruschini D, Astarita L, Parenti G, Andria G: The videofluoroscopic swallowing study shows a sustained improvement of dysphagia in children with Niemann-Pick disease type C after therapy with miglustat. Am J Med Genet A 2011, 155A:540-547

19. Jan MM, Camfield PR: Nova Scotia Niemann-Pick disease (type D): clinical study of 20 cases. J Child Neurol 1998, 13:75-78.

20. Kelly DA, Portmann B, Mowat AP, Sherlock S, Lake BD: Niemann-Pick disease type $C$ : diagnosis and outcome in children, with particular reference to liver disease. J Pediatr 1993, 123:242-247.

21. Marik PE: Aspiration pneumonitis and aspiration pneumonia. N Engl J Med 2001, 344:665-671.

22. Petroianni A, Ceccarelli D, Conti V, Terzano C: Aspiration pneumonia. Pathophysiological aspects, prevention and management. A review. Panminerva Med 2006, 48:231-239.

23. Miglustat (Zavesca) Summary of Product Characteristics. [http://eudrapharm eu/eudrapharm/showDocument?documentld=299255761182430949].

24. Platt FM, Neises GR, Dwek RA, Butters TD: N-butyldeoxynojirimycin is a novel inhibitor of glycolipid biosynthesis. J Biol Chem 1994, 269:8362-8365. 
25. Patterson MC, Vecchio D, Prady H, Abel L, Wraith JE: Miglustat for treatment of Niemann-Pick $C$ disease: a randomised controlled study. Lancet Neurol 2007, 6:765-772.

26. Patterson MC, Vecchio D, Jacklin E, Abel L, Chadha-Boreham H, Luzy C, Giorgino R, Wraith JE: Long-term miglustat therapy in children with Niemann-Pick disease type C. J Child Neurol 2010, 25:300-305.

27. Wraith JE, Vecchio D, Jacklin E, Abel L, Chadha-Boreham H, Luzy C, Giorgino R, Patterson MC: Miglustat in adult and juvenile patients with NiemannPick disease type C: long-term data from a clinical trial. Mol Genet Metab 2010, 99:351-357.

28. Lyu RK, Ko YM, Hung IJ, Lu CS: Type C Niemann-Pick disease: report of a Chinese case. J Formos Med Assoc 1993, 92:829-831.

29. Chien YH, Lee NC, Tsai LK, Huang AC, Peng SF, Chen SJ, Hwu WL: Treatment of Niemann-Pick disease type $C$ in two children with miglustat: initial responses and maintenance of effects over 1 year. J Inherit Metab Dis 2007, 30:826.

30. Santos ML, Raskin S, Telles DS, Lohr A Jr, Liberalesso PB, Vieira SC, Cordeiro $\mathrm{ML}$ : Treatment of a child diagnosed with Niemann-Pick disease type $C$ with miglustat: a case report in Brazil. J Inherit Metab Dis 2008, 31(Suppl 2):S357-S361.

31. Galanaud D, Tourbah A, Lehericy S, Leveque N, Heron B, de Villemeur Billette T, Guffon N, Feillet F, Baumann N, Vanier MT, Sedel F: 24 month-treatment with miglustat of three patients with Niemann-Pick disease type C: follow up using brain spectroscopy. Mol Genet Metab 2009, 96:55-58.

32. Foley N, Teasell R, Salter K, Kruger E, Martino R: Dysphagia treatment post stroke: a systematic review of randomised controlled trials. Age Ageing 2008, 37:258-264

33. Low J, Wyles C, Wilkinson T, Sainsbury R: The effect of compliance on clinical outcomes for patients with dysphagia on videofluoroscopy. Dysphagia 2001, 16:123-127.

34. Langmore SE: Dysphagia in neurologic patients in the intensive care unit Semin Neurol 1996, 16:329-340

35. Marik PE: Aspiration syndromes: aspiration pneumonia and pneumonitis Hosp Pract (Minneap) 2010, 38:35-42.

36. Daniels SK, Brailey K, Priestly DH, Herrington LR, Weisberg LA, Foundas AL: Aspiration in patients with acute stroke. Arch Phys Med Rehabil 1998, 79:14-19.

37. Bjurulf B, Spetalen S, Erichsen A, Vanier MT, Strom EH, Stromme P. Niemann-Pick disease type C2 presenting as fatal pulmonary alveolar lipoproteinosis: morphological findings in lung and nervous tissue. Medical science monitor: international medical journal of experimental and clinical research 2008, 14:CS71-CS75.

38. Harzer K, Ruprecht KW, Seuffer-Schulze D, Jans U: [Niemann-Pick disease type B: An enzymatically confirmed case with unexpected retinal involvement (author's transl)]. Albrecht von Graefe's archive for clinical and experimental ophthalmology 1978, 206:79-88.

39. Kawai K, Tsuchiyama H, Tabata K: An autopsy case of Niemann-Pick disease. Acta Pathol Jpn 1973, 23:837-846.

40. Landas S, Foucar K, Sando GN, Ellefson R, Hamilton HE: Adult Niemann-Pick disease masquerading as sea blue histiocyte syndrome: report of a case confirmed by lipid analysis and enzyme assays. Am J Hematol 1985, 20:391-400.

41. Griffiths C, Rooney C: Trends in mortality from Alzheimer's disease, Parkinson's disease and dementia, England and Wales, 1979-2004. Health statistics quarterly / Office for National Statistics 2006, 6:14.

42. Hickling $\mathrm{KG}$, Howard $\mathrm{R}$ : A retrospective survey of treatment and mortality in aspiration pneumonia. Intensive Care Med 1988, 14:617-622.

43. Finucane TE, Bynum JPW: Use of tube feeding to prevent aspiration pneumonia. Lancet 1996, 348:1421-1424.

44. Heemskerk AW, Roos RA: Dysphagia in Huntington's disease: a review. Dysphagia 2011, 26:62-66.

45. Ramsey D, Smithard D, Kalra L: Silent aspiration: what do we know? Dysphagia 2005, 20:218-225.

46. Schweitzer JK, Krivda JP, D'Souza-Schorey C: Neurodegeneration in Niemann-Pick Type $\mathrm{C}$ disease and Huntington's disease: impact of defects in membrane trafficking. Curr Drug Targets 2009, 10:653-665.

47. Chua CC, Lim ML, Wong BS: Altered apolipoprotein E glycosylation is associated with Abeta(42) accumulation in an animal model of Niemann-Pick Type C disease. J Neurochem 2010, 112:1619-1626.

48. Koh V, Cheung NS: Cellular mechanism of U18666A-mediated apoptosis in cultured murine cortical neurons: Bridging Niemann-Pick disease type C and Alzheimer's disease. Cellular Signaling 2006, 18:1844-1853.
49. Sorenson ST, Fenger K: Cause of death in patients with Huntington's disease and in unaffected first degree relatives. J Med Genet 1992, 29:911-914.

50. Brunnstrom HR, Englund EM: Cause of death in patients with dementia disorders. Eur J Neurol 2009, 16:488-492.

51. Gonzalez-Fernandez M, Kuhlemeier KV, Palmer JB: Racial disparities in the development of dysphagia after stroke: analysis of the California (MIRCal) and New York (SPARCS) inpatient databases. Arch Phys Med Rehabil 2008, 89:1358-1365.

52. Langmore SE, Grillone G, Elackattu A, Walsh M: Disorders of swallowing palliative care. Otolaryngol Clin North Am 2009, 42:87-105. ix

53. Atsuta N, Watanabe H, Ito M, Tanaka F, Tamakoshi A, Nakano I, Aoki M, Tsuji S, Yuasa T, Takano H, et al: Age at onset influences on wide-ranged clinical features of sporadic amyotrophic lateral sclerosis. J Neurol Sci 2009, 276:163-169.

54. Ahn SH, Kim DU, Kim HW: The prevention of aspiration pneumonia by early nasogastric tube feeding in acute stroke patients with dysphagia. Int J Stroke 2010, 5:225.

55. Alshekhlee A, Ranawat N, Syed TU, Conway D, Ahmad SA, Zaidat OO: National Institutes of Health stroke scale assists in predicting the need for percutaneous endoscopic gastrostomy tube placement in acute ischemic stroke. Journal of stroke and cerebrovascular diseases: the official journal of National Stroke Association 2010, 19:347-352.

56. Altman KW, Yu GP, Schaefer SD: Consequence of dysphagia in the hospitalized patient: impact on prognosis and hospital resources. Arch Otolaryngol Head Neck Surg 2010, 136:784-789.

57. Aviv JE, Sacco RL, Mohr JP, Thompson JL, Levin B, Sunshine S, Thomson J, Close LG: Laryngopharyngeal sensory testing with modified barium swallow as predictors of aspiration pneumonia after stroke. Laryngoscope 1997, 107:1254-1260

58. Chua KSG, Kong KH: Functional outcome in brain stem stroke patients after rehabilitation. Arch Phys Med Rehabil 1996, 77:194-197.

59. James A, Kapur K, Hawthorne AB: Long-term outcome of percutaneous endoscopic gastrostomy feeding in patients with dysphagic stroke. Age Ageing 1998, 27:671-676.

60. Meng N-H, Wang T-G, Lien I-N: Dysphagia in patients with brainstem stroke: Incidence and outcome. Am J Phys Med Rehabil 2000, 79:170-175.

61. Perry L, McLaren SM: Dysphagia screening, assessment and outcomes in stroke patients: Phase 1 of an evidence-based practice project. Journal of Clinical Excellence 2000, 1:201-208.

62. Schurr MJ, Ebner KA, Maser AL, Sperling KB, Helgerson RB, Harms B: Formal swallowing evaluation and therapy after traumatic brain injury improves dysphagia outcomes. J Trauma 1999, 46:817-821. discussion 821-823.

63. Spencer BR Jr, Kunimoto DY, Patel DR, Dodick DW: Acute multifocal posterior placoid pigment epitheliopathy (AMPPPE) mimicking migraine with aura. Cephalalgia: an international journal of headache 2009, 29:694-698.

64. Sung HY, Kim JS, Lee KS, Kim YI, Song IU, Chung SW, Yang DW, Cho YK, Park JM Lee IS, et al: The prevalence and patterns of pharyngoesophageal dysmotility in patients with early stage Parkinson's disease. Mov Disord 2010, 25:2361-2368.

65. Ali M, Khan Y, Khan H: Complications of cerebrovascular accident in two tertiary care hospitals of Peshawar, Pakistan. Iranian Red Crescent Medical Journal 2008, 10:261-266.

66. Amare A, Zenebe G, Hammack J: Status epilepticus: Clinical presentation cause, outcome, and predictors of death in 119 Ethiopian patients. Epilepsia 2008, 49:600-607.

67. Aslanyan S, Weir CJ, Diener HC, Kaste M, Lees KR: Pneumonia and urinary tract infection after acute ischaemic stroke: a tertiary analysis of the GAIN International trial. Eur J Neurol 2004, 11:49-53.

68. Fernandez $\mathrm{HH}$, Lapane KL: Predictors of mortality among nursing home residents with a diagnosis of Parkinson's disease. Medical science monitor: international medical journal of experimental and clinical research 2002, 8:CR241-246.

69. Marwat MA, Hussain M, Khan N: Frequency of complications of stroke. J Med Sci 2010, 18:19-21.

70. Pineda M, Wraith JE, Mengel E, Sedel F, Hwu WL, Rohrbach M, Bembi B, Walterfang M, Korenke GC, Marquardt T, et al: Miglustat in patients with Niemann-Pick disease Type C (NP-C): a multicenter observational retrospective cohort study. Mol Genet Metab 2009, 98:243-249.

71. Gates J, Hartnell GG, Gramigna GD: Videofluoroscopy and swallowing studies for neurologic disease: a primer. Radiographics: a review publication of the Radiological Society of North America, Inc 2006, 26:e22. 
72. Han TR, Paik NJ, Park JW: Quantifying swallowing function after stroke: A functional dysphagia scale based on videofluoroscopic studies. Arch Phys Med Rehabil 2001, 82:677-682.

73. Fecarotta S, Astarita L, Bruschini D, Pisani L, Romano A, Del Giudice E, Mansi G, Amitrano M, Dolezalova H, Della Casa R, et al: Efficacy of miglustat on the neurological involvement in Italian patients with Niemann-pick disease type C. Mol Genet Metab 2009, 98:70.

74. Hollak CE, Hughes D, van Schaik IN, Schwierin B, Bembi B: Miglustat (Zavesca) in type 1 Gaucher disease: 5-year results of a postauthorisation safety surveillance programme. Pharmacoepidemiol Drug Saf 2009, 18:770-777.

75. Cox T, Lachmann R, Hollak C, Aerts J, van Weely S, Hrebicek M, Platt F, Butters T, Dwek R, Moyses C, et al: Novel oral treatment of Gaucher's disease with N-butyldeoxynojirimycin (OGT 918) to decrease substrate biosynthesis. Lancet 2000, 355:1481-1485.

76. Elstein D, Hollak C, Aerts JM, van Weely S, Maas M, Cox TM, Lachmann RH, Hrebicek M, Platt FM, Butters TD, et al: Sustained therapeutic effects of oral miglustat (Zavesca, N-butyldeoxynojirimycin, OGT 918) in type I Gaucher disease. J Inherit Metab Dis 2004, 27:757-766.

77. Heitner R, Elstein D, Aerts J, Weely S, Zimran A: Low-dose N-butyldeoxynojirimycin (OGT 918) for type I Gaucher disease. Blood Cells Mol Dis 2002, 28:127-133.

78. Pastores GM, Barnett NL, Kolodny EH: An open-label, noncomparative study of miglustat in type I Gaucher disease: efficacy and tolerability over 24 months of treatment. Clin Ther 2005, 27:1215-1227.

79. Belmatoug N, Burlina A, Giraldo P, Hendriksz CJ, Kuter DJ, Mengel E, Pastores GM: Gastrointestinal disturbances and their management in miglustat-treated patients. J Inherit Metab Dis 2011, 34:991-1001.

80. Champion H, Ramaswami U, Imrie J, Lachmann RH, Gallagher J, Cox TM, Wraith JE: Dietary modifications in patients receiving miglustat. J Inherit Metab Dis 2010, doi:doi: 10.1007/s10545-008-0923-9 [Epub ahead of print].

81. Chio A, Calvo A, Ghiglione P, Mazzini L, Mutani R, Mora G: Tracheostomy in amyotrophic lateral sclerosis: a 10-year population-based study in Italy. J Neurol Neurosurg Psychiatry 2010, 81:1141-1143.

82. Gil J, Funalot B, Verschueren A, Danel-Brunaud V, Camu W, Vandenberghe N, Desnuelle C, Guy N, Camdessanche JP, Cintas P, et al: Causes of death amongst French patients with amyotrophic lateral sclerosis: a prospective study. Eur J Neurol 2008, 15:1245-1251.

83. Lewis D, Ampong MA, Rio A, Willey E, Johnson J, Shaw CE, Ellis CM, Al-Chalabi A, Leigh PN, Sidhu PS: Mushroom-cage gastrostomy tube placement in patients with amyotrophic lateral sclerosis: a 5-year experience in 104 patients in a single institution. Eur Radio/ 2009, 19:1763-1771

84. Lo Coco D, Marchese S, La Bella V, Piccoli T, Lo Coco A: The amyotrophic lateral sclerosis functional rating scale predicts survival time in amyotrophic lateral sclerosis patients on invasive mechanical ventilation. Chest 2007, 132:64-69.

85. Lipe H, Bird T: Late onset Huntington Disease: clinical and genetic characteristics of 34 cases. J Neurol Sci 2009, 276:159-162.

86. Deshpande R, Kremenchutzky M, Rice GP: The natural history of multiple sclerosis. Adv Neurol 2006, 98:1-15.

87. Ebers GC, Reder AT, Traboulsee A, Li D, Langdon D, Goodin DS, Wolf C, Beckmann K, Konieczny A: Long-term follow-up of the original interferonbeta1b trial in multiple sclerosis: design and lessons from a 16-year observational study. Clin Ther 2009, 31:1724-1736.

88. Farge D, Labopin M, Tyndall A, Fassas A, Mancardi GL, Van Laar J, Ouyang J, Kozak T, Moore J, Kotter I, et al: Autologous hematopoietic stem cell transplantation for autoimmune diseases: an observational study on 12 years' experience from the European Group for Blood and Marrow Transplantation Working Party on Autoimmune Diseases. Haematologica 2010, 95:284-292.

89. Smestad C, Sandvik L, Celius EG: Excess mortality and cause of death in a cohort of Norwegian multiple sclerosis patients. Mult Scler 2009, 15:1263-1270.

90. Sumelahti ML, Hakama M, Elovaara I, Pukkala E: Causes of death among patients with multiple sclerosis. Mult Scler 2010, 16:1437-1442.

91. Pennington S, Snell K, Lee M, Walker R: The cause of death in idiopathic Parkinson's disease. Parkinsonism Relat Disord 2010, 16:434-437.

92. D'Amelio M, Ragonese P, Morgante L, Reggio A, Callari G, Salemi G, Savettieri G: Long-term survival of Parkinson's disease: a populationbased study. J Neurol 2006, 253:33-37.
93. Das SK, Misra AK, Ray BK, Hazra A, Ghosal MK, Chaudhuri A, Roy T, Banerjee TK, Raut DK: Epidemiology of Parkinson disease in the city of Kolkata, India: a community-based study. Neurology 2010, 75:1362-1369.

94. Diem-Zangerl A, Seppi K, Oberaigner W, Poewe W: Mortality in Parkinson's disease, a 20-year follow-up study. Mov Disord 2010, 25:661-662.

95. Driver JA, Kurth T, Buring JE, Gaziano JM, Logroscino G: Parkinson disease and risk of mortality: a prospective comorbidity-matched cohort study. Neurology 2008, 70:1423-1430.

96. Fall PA, Saleh A, Fredrickson M, Olsson JE, Granerus AK: Survival time, mortality, and cause of death in elderly patients with Parkinson's disease: a 9-year follow-up. Mov Disord 2003, 18:1312-1316.

97. Gray WK, Hildreth A, Bilclough JA, Wood BH, Baker K, Walker RW: Physical assessment as a predictor of mortality in people with Parkinson's disease: a study over 7 years. Mov Disord 2009, 24:1934-1940.

98. Grytten TN, Lie SA, Aarseth JH: Survival and cause of death in multiple sclerosis: Results from a 50-year follow-up in Western Norway. Mult Scler 2008, 14:1191-1198.

99. Hirst C, Swingler R, Compston DA, Ben-Shlomo Y, Robertson NP: Survival and cause of death in multiple sclerosis: a prospective population-based study. J Neurol Neurosurg Psychiatry 2008, 79:1016-1021.

100. Schupbach MW, Welter ML, Bonnet AM, Elbaz A, Grossardt BR, Mesnage V Houeto $J$, Maltete D, Mallet L, Rocca WA, et al: Mortality in patients with Parkinson's disease treated by stimulation of the subthalamic nucleus. Mov Disord 2007, 22:257-261.

101. Vergani F, Landi A, Pirillo D, Cilia R, Antonini A, Sganzerla EP: Surgical, medical, and hardware adverse events in a series of 141 patients undergoing subthalamic deep brain stimulation for Parkinson disease. World Neurosurg 2010, 73:338-344.

102. Wider C, Pollo C, Bloch J, Burkhard PR, Vingerhoets FJ: Long-term outcome of 50 consecutive Parkinson's disease patients treated with subthalamic deep brain stimulation. Parkinsonism Relat Disord 2008, 14:114-119.

103. Amin MR, Harris D, Cassel SG, Grimes E, Heiman-Patterson T: Sensory testing in the assessment of laryngeal sensation in patients with amyotrophic lateral sclerosis. Ann Otol Rhinol Lanyngol 2006, 115:528-534.

104. Fattori $B$, Grosso M, Bongioanni $P$, Nacci A, Cristofani R, AlSharif A, Licitra $R$, Matteucci F, Rossi B, Rubello D, et al: Assessment of swallowing by oropharyngoesophageal scintigraphy in patients with amyotrophic lateral sclerosis. Dysphagia 2006, 21:280-286.

105. Goh KJ, Tian S, Shahrizaila N, Ng CW, Tan CT: Survival and prognostic factors of motor neuron disease in a multi-ethnic Asian population. Amyotrophic lateral sclerosis: official publication of the World Federation of Neurology Research Group on Motor Neuron Diseases 2011, 12:124-129.

106. Larson S, Tiryaki E: Diet at time of procedure predicts complications after percutaneous endoscopic gastrostomy placement in ALS. Amyotroph Lateral Scler 2009, 10(Suppl 1):53-54.

107. Nakayama Y, Ogura A, Matsuda C: Oral Secretions Scale - Test-Re-Test Reliability pilot study in a Japanese amyotrophic lateral sclerosis population. Amyotroph Lateral Scler 2010, 11(Suppl 1):141.

108. Nozaki S, Sugishita S, Saito T, Umaki Y, Adachi K, Shinno S: Prolonged apnea/hypopnea during water swallowing in patients with amyotrophic lateral sclerosis. Rinsho shinkeigaku = Clinical neurology 2008, 48:634-639.

109. de Rivera Rodriguez FJ, Sanz G, Oreja GC: Influence of physical activity in the evolution of ALS. Amyotroph Lateral Scler 2010, 11(1):123.

110. Tomik J, Tomik B, Skladzien J, Gajec S, Strek P, Oles K, Gawlik J, Wiatr M: [Analysis of oropharyngeal phase of swallowing in patients with amyotrophic lateral sclerosis]. Przegl Lek 2009, 66:905-908.

111. Werneck LC, Bezerra R, Silveira Neto O, Scola RH: A clinical epidemiological study of 251 cases of amyotrophic lateral sclerosis in the south of Brazil. Arq Neuropsiquiatr 2007, 65:189-195.

112. Aziz NA, Anguelova GV, Marinus J, van Dijk JG, Roos RA: Autonomic symptoms in patients and pre-manifest mutation carriers of Huntington's disease. Eur J Neurol 2010, 17:1068-1074.

113. Guo X, Zhang S, Burgunder J-M: Clinical features of Huntington disease in 243 Chinese patients. Neural Regeneration Research 2010, 5:102-107.

114. Guo X-Y, Zhang S-S, Zhao B: Clinical features of Huntington's disease in 241 Chinese patients. Mov Disord 2010, 25(Suppl 2):S276.

115. Bergamaschi R, Crivelli P, Rezzani C, Patti F, Solaro C, Rossi P, Restivo D, Maimone D, Romani A, Bastianello S, et al: The DYMUS questionnaire for the assessment of dysphagia in multiple sclerosis. J Neurol Sci 2008, 269:49-53. 
116. Bergamaschi R, Rezzani C, Minguzzi S, Amato MP, Patti F, Marrosu MG, Bonavita S, Grasso MG, Ghezzi A, Rottoli M, et al: Validation of the DYMUS questionnaire for the assessment of dysphagia in multiple sclerosis. Funct Neurol 2009, 24:159-162.

117. Poorjavad M, Derakhshandeh F, Etemadifar M, Soleymani B, Minagar A, Maghzi AH: Oropharyngeal dysphagia in multiple sclerosis. Mult Scler 2010, 16:362-365.

118. Solaro C, Rezani C, Bergamaschi R: Prevalence of dysphagia [sic] in multiple sclerosis: An Italian multicentre study. Mult Scler 2009, 15:S259-S260.

119. Vazirinejad R, Lilley J, Ward C: A health profile of adults with multiple sclerosis living in the community. Mult Scler 2008, 14:1099-1105.

120. Chinnery PF, Crompton DE, Birchall D, Jackson MJ, Coulthard A, Lombes A, Quinn N, Wills A, Fletcher N, Mottershead JP, et al: Clinical features and natural history of neuroferritinopathy caused by the FTL1 460InsA mutation. Brain 2007, 130:110-119.

121. Fiorenza D, Vitacca M, Bianchi L, Gabbrielli L, Ambrosino N: Lung function and disability in neuromuscular patients at first admission to a respiratory clinic. Respir Med 2011, 105:151-158.

122. Althaus A, Becker OA, Spottke A, Dengler R, Schneider F, Kloss M, Eggert K, Oertel WH, Dillmann U, Herting B, et al: Frequency and treatment of depressive symptoms in a Parkinson's disease registry. Parkinsonism Relat Disord 2008, 14:626-632.

123. Choi M-G, Park JM, Cho YK: Manometry and impedance characteristics of the esophagus in patients with early stage of idiopathic Parkinson's disease. Gastroenterology 2009, 136:A92-A93.

124. Coelho M, Marti MJ, Tolosa E, Ferreira JJ, Valldeoriola F, Rosa M, Sampaio C: Late-stage Parkinson's disease: the Barcelona and Lisbon cohort. J Neurol 2010, 257:1524-1532.

125. Felix VN, Correa SM, Soares RJ: A therapeutic maneuver for oropharyngeal dysphagia in patients with Parkinson's disease. Clinics (Sao Paulo) 2008, 63:661-666

126. Galazky I, Vorwerk W, Voges J: Dysphagia in Parkinson's disease improves by subthalamic high frequency stimulation. Mov Disord 2010, 25(Suppl 2):S443.

127. Gross RD, Atwood CW Jr, Ross SB, Eichhorn KA, Olszewski JW, Doyle PJ: The coordination of breathing and swallowing in Parkinson's disease. Dysphagia 2008, 23:136-145.

128. Kalf JG, de Swart BJ, Borm GF, Bloem BR, Munneke M: Prevalence and definition of drooling in Parkinson's disease: a systematic review. J Neurol 2009, 256:1391-1396.

129. Kelchner LN: Use of thickened liquids versus postural change as an immediate intervention for thin-liquid aspiration in individuals with neurogenic dysphagia: No easy answers. Evidence-Based Communication Assessment and Intervention 2009, 3:19-23.

130. Lam K, Lam FK, Lau KK, Chan YK, Kan EY, Woo J, Wong FK, Ko A: Simple clinical tests may predict severe oropharyngeal dysphagia in Parkinson's disease. Mov Disord 2007, 22:640-644.

131. Lo RY, Tanner CM, Albers KB, Leimpeter AD, Fross RD, Bernstein AL, McGuire V, Quesenberry CP, Nelson LM, Van Den Eeden SK: Clinical features in early Parkinson disease and survival. Arch Neurol 2009, 66:1353-1358.

132. Manor Y, Balas M, Giladi N, Mootanah R, Cohen JT: Anxiety, depression and swallowing disorders in patients with Parkinson's disease. Parkinsonism Relat Disord 2009, 15:453-456.

133. Manor Y, Giladi N, Cohen A, Fliss DM, Cohen JT: Validation of a swallowing disturbance questionnaire for detecting dysphagia in patients with Parkinson's disease. Mov Disord 2007, 22:1917-1921.

134. Miller N, Allcock L, Hildreth AJ, Jones D, Noble E, Burn DJ: Swallowing problems in Parkinson disease: frequency and clinical correlates. J Neurol Neurosurg Psychiatry 2009, 80:1047-1049.

135. Nicaretta DH, Rosso ALZ, De Mattos JP: Dysphagia and sialorrhea associated with Parkinson's disease. Mov Disord 2010, 25(Suppl 2):S333.

136. Nobrega AC, Rodrigues B, Melo A: Silent aspiration in Parkinson's disease patients with diurnal sialorrhea. Clin Neurol Neurosurg 2008, 110:117-119.

137. Nobrega AC, Rodrigues B, Melo A: Does botulinum toxin injection in parotid glands interfere with the swallowing dynamics of Parkinson's disease patients? Clin Neurol Neurosurg 2009, 111:430-432

138. Nobrega AC, Rodrigues B, Torres AC, Scarpel RD, Neves CA, Melo A: Is drooling secondary to a swallowing disorder in patients with Parkinson's disease? Parkinsonism Relat Disord 2008, 14:243-245.

139. Perez-Lloret S, Negre-Pages L, Merello M: Dysphagia and hypersalivation in Parkinson's disease: A cross-sectional survey. Eur J Neurol 2009, 16:608.
140. Rozenberg E, Mirelman A, Levy S: Clinical manifestation of patients with Parkinson's disease carriers of nullseverenull mutations in the GBA gene. Mov Disord 2010, 25(Suppl 2):S473.

141. Warnecke T, Oelenberg S, Teismann I, Hamacher C, Lohmann H, Ringelstein EB, Dziewas R: Endoscopic characteristics and levodopa responsiveness of swallowing function in progressive supranuclear palsy. Mov Disord 2010, 25:1239-1245.

142. Kumar A, Kumar R, Kumar U: A retrospective study about characteristics of Wilson's disease at tertiary care institute of North India. Mov Disord 2010, 25(Suppl 2):S260.

doi:10.1186/1750-1172-7-76

Cite this article as: Walterfang et al:: Dysphagia as a risk factor for mortality in Niemann-Pick disease type C: systematic literature review and evidence from studies with miglustat. Orphanet Journal of Rare Diseases 2012 7:76.

\section{Submit your next manuscript to BioMed Central and take full advantage of:}

- Convenient online submission

- Thorough peer review

- No space constraints or color figure charges

- Immediate publication on acceptance

- Inclusion in PubMed, CAS, Scopus and Google Scholar

- Research which is freely available for redistribution

Submit your manuscript at www.biomedcentral.com/submit
C) Biomed Central 